DIVISION OF THE HUMANITIES AND SOCIAL SCIENCES

CALIFORNIA INSTITUTE OF TECHNOLOGY

PASADENA, CALIFORNIA 91125

Static and Dynamic Underinvestment: An Experimental Investigation

Marina Agranov

Caltech

Guillaume Frechette

New York University

Thomas Palfrey

Caltech

Emanuel Vespa

University California Santa Barbara

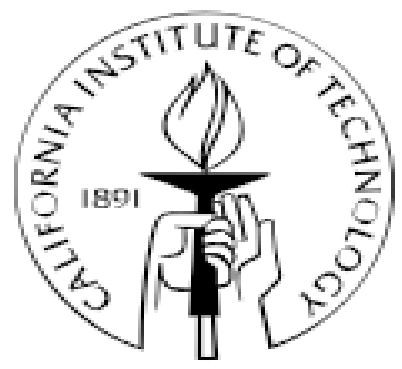

SOCIAL SCIENCE WORKING PAPER 1399

January, 2015 


\title{
Static and Dynamic Underinvestment: An Experimental Investigation*
}

\author{
Marina Agranov Guillaume Fréchette \\ Caltech NYU \\ Thomas Palfrey Emanuel Vespa \\ Caltech UCSB
}

December 18, 2014

\begin{abstract}
In this paper we design a stylized version of an environment with public goods, dynamic linkages, and legislative bargaining. Our theoretical framework studies the provision of a durable public good as a modified version of Battaglini et al. (2012). We develop an experimental design that allows us to disentangle inefficiencies that would result in a one-shot world (static inefficiencies) from extra inefficiencies that emerge in an environment in which decisions in the present affect the future (dynamic inefficiencies). We solve for efficiency and also characterize the bargaining equilibrium, a symmetric stationary subgame-perfect equilibrium, which is the most common concept used in applied work. The experimental results indicate that subjects do react to dynamic linkages and, as such, we find evidence of both static and dynamic inefficiencies. In fact, the quantitative predictions of the model with respect to the share of dynamic inefficiencies are closest to the data when dynamic linkages are high. To the extent that behavior is different from what is predicted by the model, a systematic pattern emerges, namely the use of strategic cooperation whereby subjects increase the efficiency of period one proposals by selectively punishing, in period two, subjects who did not propose efficient allocations.
\end{abstract}

\footnotetext{
${ }^{*}$ Research support from the Center for Experimental Social Science (CESS) at NYU and the Hacker Social Science Experimental Laboratory (SSEL) at Caltech is acknowledged. We thank Matan Tsur, Sevgi Yuksel for comments and research assistance. We have benefited from comments by Nels Christensen, John Kagel, Erkut Ozbay, Charlie Plott, Sergio Vicente, Christoph Vanberg, Alistair Wilson and participants at the 2012 ESA North American Meetings, 2013 workshop on Behavioral Public Economics at Vienna U., 2013 ASSA San Diego Meetings, 2013 Public Choice Society Meetings, and the 2013 Caltech Conference on Experimental Political Economy. Fréchette is grateful for financial support from the NSF, the CV Starr Center, and CESS. Palfrey is grateful for financial support in the form of grants from from NSF, the Gordon and Betty Moore Foundation, and the Russell Sage Foundation. Agranov: magranov@hss.caltech.edu; Fréchette: frechette@nyu.edu; Palfrey: trp@hss.caltech.edu; Vespa: vespa@ucsb.edu.
} 


\section{Introduction}

Many important public goods are supplied by the government and thus are determined via a legislative process. Furthermore, most of these public goods are long lived and cannot be appropriately considered in the context of a one-shot decision. Rather, over time, the legislature must repeatedly determine how much resources to allocate to such public goods, and prior investments in the public good have impacts beyond the moment where the investment is made. There have been recent developments in economic theory integrating these factor in models of public good provision with dynamic linkages. Indeed, papers in political economy such as Battaglini and Coate (2008) recognize the importance of dynamic linkages and provide an analysis of these type of situations. Once the setting is a dynamic one, there are multiple channels that generate inefficiencies, or differences between the equilibrium level of public goods and the one a central planner would select. In particular, agents not only wish to free-ride with respect to other agents' contribution in the current period, but also with respect to the contributions of agents in the future.

In this paper we design a stylized version of an environment with public goods, dynamic linkages, and legislative bargaining. The goal is to simplify the environment while maintaining some of the key features present in models such as Battaglini and Coate (2008). More precisely, our theoretical framework studies the provision of a durable public good as a modified version of Battaglini et al. (2012). We develop an experimental design that allows us to disentangle inefficiencies that would result in a one-shot world (static inefficiencies) from extra inefficiencies that emerge in an environment in which decisions in the present affect the future (dynamic inefficiencies). Note that such a question is particularly relevant given the frequent observation that free-ridding is much less severe in public good experiments than the theory suggests. Hence, one may wonder if the more subtle issue of dynamic free ridding is something people even take into consideration. The setting put forth to investigate this question is simple. In each of two periods of time, a committee decides on the allocation of a fixed budget over a public good and private consumption for each member. The division is determined by majority rule using the multilateral bargaining procedure of Baron and Ferejohn (1989). ${ }^{1}$ The dynamic link is provided by the public good, as a portion $\delta \in(0,1)$ of the first period investment survives and is available in period 2. In other words, the level of the public good in period 2 equals the portion that survived from period 1 plus period 2 investment. We solve for efficiency and also characterize the bargaining equilibrium, a symmetric stationary subgame perfect equilibrium, which is the most common concept used in applied work.

In the bargaining equilibrium, investment is distorted away from the first best. To see why, consider first the case in which no portion of the public good survives $(\delta=0)$. When the planner decides how to allocate the budget, she considers the benefit that an additional unit of investment has for all committee members. With bargaining being settled by majority rule, however, the equilibrium results from computing the investment benefits to a minimum winning coalition (MWC). The consequence is underinvestment or static inefficiencies.

\footnotetext{
${ }^{1}$ One member chosen at random submits an allocation proposal that is then voted on by all committee members. If the proposal does not achieve a simple majority of votes, it is rejected, and the process repeats itself.
} 
When the public good is durable $(\delta \in(0,1))$ there is an obvious incentive for higher investment in period 1 , but also new sources of underinvestment. A suboptimal period 1 choice will now affect future choices. In the bargaining equilibrium, the committee will start in period 2 with a lower level of the public good, constraining the set of options for that period with respect to the efficient solution. The planner in a dynamic setting considers the effect that current decisions have on all committee members in the present and in the future. But, again, in the bargaining equilibrium, period 1 decisions are only concerned with the present and the future of a subset of members, namely, those in the MWC.

We will use the term dynamic inefficiencies to account for any underinvestment that results on top of static inefficiencies, where static inefficiencies are the ones that emerge when public goods do not affect payoffs for more than a single period. In the bargaining equilibrium, dynamic inefficiencies can represent a very large portion of total inefficiencies. For example, in our parametrization, if only $80 \%$ of period 1 investment survives in period 2, dynamic inefficiencies account for approximately three-quarters of the total inefficiencies. Our theoretical environment provides a very conservative measure of dynamic underinvestment. First, we use a two-period model as it is the simplest environment in which dynamic effects arise, but the inefficiency gap increases with the time horizon. Second, in our experiments committees involve three members, but dynamic inefficiencies increase with committee size. In other words, findings in line with dynamic inefficiency predictions in our setting are suggestive of an even greater role for the practical relevance of dynamic effects in general.

Our experimental design allows us to disentangle the static from the dynamic component. The control treatment sets $\delta=0$ and will provide us with a measure of static underinvestment. We also study in the laboratory the cases $\delta \in\{0.2,0.8\}$, so that we can compute dynamic underinvestment in two treatments. Moreover, our treatments allow us to study the comparative statics of $\delta$. As the value of $\delta$ increases, dynamic inefficiencies as a share of total inefficiencies also increase in the bargaining equilibrium prediction.

The key results with respect to public good investment in period one can be summarized as follows. In our control treatment $(\delta=0)$, mean and median public good investments are not statistically different from those predicted by theory. ${ }^{2}$ When comparing investment against the static benchmark, our evidence suggests that there are two main differences stemming from a dynamic environment. First, there is a sizable presence of period one proposals (up to 60\%) that benefit all members equally, with investment levels close to efficiency. In other words, when the benefits of period one investment in the public good increase, the proportion of subjects submitting proposals with MWCs decrease. Second, as $\delta$ increase, there is more heterogeneity in period 1 investment. $^{3}$ A prominent finding in our dynamic treatments is the presence of strategic cooperation. Most subjects who make proposals with period 1 investment close to efficiency propose a MWC in period 2 , i.e. they are not unconditional altruists. On average, those subjects use the period 2 proposal to

\footnotetext{
${ }^{2}$ Other aspects of behavior are similar to what has been reported in legislative bargaining games without public good (see for instance Fréchette et al. (2003)): a majority of proposals are approved immediately, 70\% of proposals involve MWCs, and there is evidence of proposal power but the advantage is well below the theoretical prediction.

${ }^{3} \mathrm{Also}$, in dynamic environments, there is no evidence of proposer power in private allocations.
} 
punish those period 1 proposers who did not select high investment, and reward those who did, by strategically including them in period 2's MWC. Theoretically, this strategy is not subgame perfect. In our data, given the choices of other participants, the payoff difference with respect to those proposing MWCs is not large. Therefore, it is not unreasonable that a large proportion of subjects would select strategic cooperative proposals even after substantial experience with the environment.

Despite the heterogeneity in individual behavior, the bargaining equilibrium prediction on the share of dynamic inefficiencies is quite accurate when dynamic linkages are high. The presence of proposals with investment levels close to the planner's solution reduces the size of inefficiencies when we aggregate the data. However, dynamic inefficiencies as a share of total inefficiencies are at $75 \%$, quite close to the theoretical prediction of $72 \%$. In other words, when dynamic linkages are high, inefficiencies introduced by the dynamic structure represent a sizable portion of total inefficiencies, as predicted by the bargaining equilibrium. When dynamic linkages are relatively low, dynamic inefficiencies become less prominent.

Our work is related to previous work on public good provision in static and dynamic settings. With respect to the former, our baseline treatment provides a setup in which the main theoretical prediction and the efficient solution involve interior investment levels. These features contrast with the usual framework used to study public goods, the linear public good game (or voluntary contribution mechanism - VCM). In that model the dominant strategy and the efficient outcome are at the boundary of the action space, with an equilibrium prediction of no investment and an efficient outcome involving full provision. In such a setup, experiments show that investment in the public good remains positive even when participants have experience (see Ledyard (1995) and Vesterlund (2013)). Recent studies of public goods games modify the original VCM to have an interior solution in dominant strategies (see for instance Menietti et al. (2014)). Our work adds to this literature by also providing a static framework with interior solutions in which to study public good provision. Despite the equilibrium of our game not being in dominant strategies, contributions to the public good in the static treatment are much closer to equilibrium levels than in typical VCM experiments. Similarly studies such as Menietti et al. (2014) report results close to equilibrium. The fact that both ours and other studies find congruent results in this regard highlight the importance of the specific details of the game in earlier results.

This paper is also related to a literature studying public good provision in committees. Fréchette et al. (2012) implement in the laboratory a model of static public good provision with multilateral bargaining (Volden and Wiseman (2007)). Our work is also related to a recent literature on public good provision in dynamic settings. ${ }^{4}$ Most closely related is the work of Battaglini et al. (2012). They study theoretically and experimentally the accumulation of a durable public good under different voting rules, using a centralized mechanism for public good provision similar to the one we use in this paper, but with an infinite time horizon. They find that players' choices reflect nonmyopic decision making. Choices are quantitatively close to the predictions of the solution concept

\footnotetext{
${ }^{4}$ Contributions in this area include: Herr et al. (1997); Noussair and Matheny (2000); Lei and Noussair (2002); Battaglini and Palfrey (2012); Battaglini et al. (2013, 2014a); Saijo et al. (2013); Vespa (2014).
} 
most commonly used in the literature (Markov perfect equilibrium) and imply the existence of inefficiencies. This paper contributes to this literature by disentangling static from dynamic forces behind underinvestment.

The plan of the paper is as follows: Section 2 outlines the model that serves as our benchmark. Sections 3, 4 and 5 give the experimental design and the results, respectively. A brief discussion of our results is reported in Section 6.

\section{Theoretical Framework}

As mentioned in the introduction, the model is meant to simplify dynamic models of public good provision while retaining the key strategic tensions of such an environment. The game is a two-period model $(t=1,2)$ of multilateral bargaining with $n$ (odd) committee members indexed by $i$, each representing one district. There is no discounting between periods. In period $t$ the committee decides on how to allocate a fixed budget $B_{t}$ between pork to each member denoted by $x_{i t}$, and investment in a durable public good, $I_{t}$. Furthermore consumption and investment must be non-negative in

both periods, and there is no borrowing or lending. That is, $x_{i t} \geq 0, I_{t} \geq 0, \sum_{i=1}^{n} x_{i t}+I_{t} \leq B_{t}$, $t=1,2$. Investment accumulates in time and the resulting stock represents the level of the public good, $g_{t}$.

The utility of member $i$ in period $t$ is given by

$$
U_{i t}\left(x_{i t}, g_{t}\right)=x_{i t}+u\left(g_{t}\right)
$$

where $u\left(g_{t}\right)$ represents utility from the public good investment. We assume $u$ is twice continuously differentiable and has standard properties: $u^{\prime}\left(g_{t}\right)>0, u^{\prime \prime}\left(g_{t}\right)<0$ for all $g_{t}>0$ and $\lim _{g_{t} \rightarrow 0} u^{\prime}\left(g_{t}\right)=$ $\infty$. The committee starts with zero stock of public good $\left(g_{0}=0\right)$ and in period 1 the level of the public good is equal to that period's investment $\left(g_{1}=I_{1}\right)$. A portion $\delta \in[0,1]$ of the first period's investment survives and is still available in period 2 , so the depreciation rate is $d=1-\delta$. The stock of the public good in period 2 is given by $g_{2}=\delta g_{1}+I_{2}=\delta I_{1}+I_{2}$. If the public good does not fully depreciate $(\delta>0)$ between periods, the problem is dynamic.

In the remainder of this section we characterize and compare public good investments that arise from the bargaining process with the efficient levels implemented by the social planner. We present here the main trade-offs of the model and refer the reader to Appendix A for complete proofs. Our discussion is focused on understanding the sources and the determinants of the inefficiencies in public good provision due to the dynamic nature of bargaining process.

\subsection{Efficient Solution}

The Planner chooses investment levels and private allocations for each member so as to maximize welfare of the society (aggregate utility of agents) subject to budget constraint and the rule that governs the accumulation of the stock of public good. Since agents' utilities depend linearly on the 
private allocations, the planner's solution pins down the efficient level of investment in each period $\left(I_{1}^{P^{*}}, I_{2}^{P^{*}}\right)$ but is silent regarding how the remaining funds are distributed between agents in private shares.

$$
\begin{gathered}
\max _{\left(\left\{x_{i j}, I_{j}^{P}\right\}_{j=1, ., 2}^{i=n}\right)}\left[\sum_{i=1}^{n} x_{i 1}+n \cdot u\left(g_{1}\right)+\sum_{i=1}^{n} x_{i 2}+n \cdot u\left(g_{2}\right)\right] \\
\text { s.t. } \sum_{i=1}^{n} x_{i 1}+I_{1}^{P} \leq B_{1} \text { and } \sum_{i=1}^{n} x_{i 2}+I_{2}^{P} \leq B_{2} \\
I_{1}^{P} \geq 0, I_{2}^{P} \geq 0, x_{i j} \geq 0 \forall i, j \\
\text { where } g_{1}=I_{1}^{P} \text { and } g_{2}=\delta g_{1}+I_{2}^{P}
\end{gathered}
$$

The Planner's solution depends on whether and which constraints are binding. If no constraints are binding, then there is an interior solution, $\left(I_{1}^{P^{*}}, I_{2}^{P^{*}}\right)$, characterized by two first-order conditions that capture familiar trade-off:

$$
\begin{array}{ll}
\text { period 2: } & n \cdot u^{\prime}\left(\delta I_{1}^{P^{*}}+I_{2}^{P^{*}}\right)=1 \\
\text { period 1: } & n \cdot\left[u^{\prime}\left(I_{1}^{P^{*}}\right)+\delta u^{\prime}\left(\delta I_{1}^{P^{*}}+I_{2}^{P^{*}}\right)\right]=1
\end{array}
$$

This interior level of public good provision equates in each period the social marginal value of an additional unit of investment and its social marginal cost, which equals 1 in both periods. The marginal benefit of extra unit of public good in period 2 is simply $n \cdot u^{\prime}\left(\delta I_{1}^{P^{*}}+I_{2}^{P^{*}}\right)$, as it benefits equally all $n$ members of the committee. In period 1, however, there is an additional term, which represents the effect of the public investment in period 1 that partially survives until period $2 .{ }^{5}$

If the solution is not interior, then which constraint is binding depends on parameters $\left(B_{1}, B_{2}, \delta\right)$. When available budgets $\left(B_{1}, B_{2}\right)$ are sufficiently small the planner allocates all available funds to public good provision. If this is not the case, then depending on the depreciation rate, the planner might choose to allocate a portion of period 2's budget to public investment or distribute all available budget in private shares. For sufficiently high rates of public good survival $\delta$ it is efficient not to invest at all in the public good in period 2, while for low $\delta$ efficient solution has $I_{2}^{P^{*}}>0$. In any case, our assumptions on $u$ implies a unique planner solution $\left(I_{1}^{P^{*}}, I_{2}^{P^{*}}\right)$.

\subsection{Bargaining Solution}

We model the bargaining process following the classical model of Baron and Ferejohn (1989). In each period there is a (potentially) infinite number of bargaining stages. At the beginning of each stage one committee member is chosen at random to make a proposal $\left(\left\{x_{i t}\right\}_{i=1}^{i=n}, g_{t}\right)$, which is then voted on by all members of the committee. If a simple majority votes in favor, then the proposal

\footnotetext{
${ }^{5}$ Notice that if there is no depreciation $(\delta=1)$, then one of the constraints must be binding because the first order condition for period one reduces to $u^{\prime}\left(I_{1}^{P^{*}}\right)=0$, which cannot arise.
} 
is implemented and the period ends. If it is voted down, then another bargaining stage (within the same period) starts with a randomly selected member who submits a proposal and the process repeats itself. ${ }^{6}$ A portion of the public investment in period $t-1$ survives until period $t$, which creates the link between periods. We focus on the symmetric stationary subgame-perfect equilibria with strategies that are anonymous between periods (legislative bargaining equilibrium hereafter). Given the strict concavity of $u$ the legislative bargaining equilibrium is unique in investment levels $\left(I_{1}^{L^{*}}, I_{2}^{L^{*}}\right)$.

The equilibrium of a two-period game shares two main features of the one-period game equilibrium: (1) there are no delays on the equilibrium path as proposals are passed right away, and, (2) conditional on public investment being an interior solution, the proposer enjoys higher private share than any other member of the committee. As before, we discuss here the main forces that govern public investment in each period and refer the reader to Appendix A for the detailed characterization.

Conditional on the public investment in period 1, the maximization problem of a proposer in period 2 involves choosing the cheapest proposal that will pass. There are three alternative routes the proposer can take. The first route is to invest all available funds in the public good, that is, $I_{2}^{L^{*}}=B_{2}$. This route is optimal when the stock of the public good that survived from period 1 is sufficiently low, and such proposals pass with a unanimous vote. The second route is to distribute all the available budget in private shares to form a minimum winning coalition. This strategy is optimal when the stock of public good is sufficiently high. Finally, for intermediate levels of public stock, the optimal strategy of the proposer involves investing portion of the budget in the public good, rewarding $\frac{n-1}{2}$ randomly chosen members with private shares and appropriating the remaining funds to herself. This interior level of period 2 public investment is characterized by the first order condition

$$
\text { period 2: } \quad \frac{n+1}{2} \cdot u^{\prime}\left(\delta I_{1}^{L}+I_{2}^{L^{*}}\right)=1
$$

The comparison between efficient and bargaining level of public investment in period 2 when both levels are interior is instructive (equations (1a) and (2a)). Both the social planner and a member selected to propose an allocation in the bargaining game weigh the marginal benefit of the public investment against its marginal costs. While the marginal cost of public investment us the same in both situations and equals to 1 , the marginal benefits are different. The social planner takes into account the fact that a unit of public investment benefits all $n$ committee members. On the contrary, due to the specifics of the bargaining protocol (majority voting rule), the proposer internalizes the effect on $\frac{n+1}{2}$ members only, herself and $\frac{n-1}{2}$ coalition partners. Thus, the bargaining solution underprovides the public good relative to the efficient solution in period 2. This underprovision is purely static as it is present irrespectively of the survival rate of the public good $\delta$ (which is the only dynamic component of our bargaining game). We, therefore, refer to this portion of underprovision

\footnotetext{
${ }^{6}$ It is straightforward to see that analysis presented below generalizes to any quota voting rule, where passage of a proposal requires at least $q$ supporting votes and $1 \leq q<n$.
} 
of public good as the static inefficiency.

The proposer selected in period 1 anticipates how her decisions will impact choices of proposer in period 2 through accumulation of public good that is carried over between periods given the survival rate $\delta$. When $\delta=0$ all public investment in period 1 depreciates and the two-period legislative game becomes simply the one-period legislative game repeated twice. We refer to the game with $\delta=0$ as the static game, since in this case there is no linkage between periods. ${ }^{7}$ When $\delta>0$ additional dynamic forces are at play. The first order condition that characterizes the interior equilibrium investment in period $1, I_{1}^{L^{*}}$ is:

$$
\text { period 1: } \quad \frac{n+1}{2} \cdot\left[u^{\prime}\left(I_{1}^{L^{*}}\right)+\left.\frac{d V_{2}\left(I_{1}^{L}\right)}{d I_{1}}\right|_{I_{1}^{L^{*}}}\right]=1
$$

where $V_{2}\left(I_{1}^{L}\right)$ represents the continuation value of the game at the beginning of period 2 before the proposer has been selected. The left hand side reflects the distortions from the planner's solution due to both static and dynamic free rider effects. The first term $\left(\frac{n+1}{2} u^{\prime}\left(I_{1}^{L^{*}}\right)\right)$ represents the marginal benefit of the public good in period 1 to the proposer's coalition of $\frac{n+1}{2}$ voters (again, not the social marginal benefit). This the same static distortion that arises in period 2 and is present irrespectively of value of $\delta$. The second term captures the dynamic free riding effect because it takes into account how $I_{1}^{L^{*}}$ will affect the proposer's (and her coalition partners') continuation value in period 2 .

We distinguish between two separate dynamic effects of public investment $I_{1}^{L}$ on the continuation value $V_{2}$ : the direct one, which we refer to as the durability effect and the indirect one, which we call the crowding-out effect.

The crowding-out effect arises when neither of the budget or feasibility constraints are binding, that is, $I_{1}^{L^{*}}<B_{1}$ and $I_{2}^{L^{*}}\left(I_{1}^{L^{*}}\right)>0$. In this case an increase in period 1 investment completely crowds out period 2 investment. The intuition behind this movement is that the period 1 proposer can reduce the side payments to coalition members by increasing $V_{2}\left(I_{1}^{L}\right)$ (by freeing up more period 2 budget for private allocations), and at the same time raise her own payoff.

If in equilibrium the feasibility constraint in period 2 binds, that is, $I_{2}^{L^{*}}\left(I_{1}^{L^{*}}\right)=0$, then investment in period 1 will not substitute for investment in period 2 at the margin. Hence in this case, the entire dynamic free riding effect is due to the direct durability effect. The portion of public underprovision due to the durability effect is larger when the survival rate $\delta$ is smaller.

To summarize, the bargaining solution in both periods underprovides the public good relative to the efficient planner's solution. One portion of this underprovision is static since it arises irrespectively of the ties between periods (captured by parameter $\delta$ in our game). The other portion, present only in period 1, is dynamic and arises either due to the direct durability effect or due to the indirect crowding-out effect. In the next section we discuss how one can separate these parts of the free riding problem and estimate their magnitudes.

\footnotetext{
${ }^{7}$ Recall that we restricted our attention to the stationary sub-game perfect equilibria in which strategies cannot condition on the identities of the committee members in the previous period.
} 


\subsection{Identification of dynamic inefficiencies}

This paper aims to determine if subjects react to the dynamic aspects of public goods provision. If they do, are there reactions to the static and dynamic free-ridding incentives similar to what theory predicts as parameters of the environment change? Following the theoretical framework presented above, we focus on the distortions in public good provision in period 1 and propose one natural way to disentangle two source of inefficiencies (static versus dynamic), both of which contribute to the low level of public good investment relative to the efficient solution.

Let $\Delta_{1}^{S}$ capture the difference in public good investment in period 1 between the efficient and bargaining solutions when public good fully depreciates between periods $(\delta=0)$. This is pure static inefficiency, since it arises as a result of the proposer taking into account his influence only on the utility of $\frac{n+1}{2}$ members of the committee in the current period and ignores the rest of the legislators. Thus,

$$
\Delta_{1}^{S}=\left.I_{1}^{P^{\star}}\right|_{\delta=0}-\left.I_{1}^{L^{\star}}\right|_{\delta=0}
$$

When a portion of the public good investment survives between periods, i.e. $\delta>0$, the difference between the planner's and bargaining investments in period 1 encompasses both static and dynamic inefficiencies. We denote this amount by $\Delta_{1}^{T}$ and refer to it as the total inefficiencies

$$
\Delta_{1}^{T}=\left.I_{1}^{P^{\star}}\right|_{\delta>0}-\left.I_{1}^{L^{\star}}\right|_{\delta>0}
$$

Subtracting static portion of inefficiencies from the total ones gives us the dynamic inefficiencies that arise only in the dynamic setup

$$
\Delta_{1}^{D}=\Delta_{1}^{T}-\Delta_{1}^{S}
$$

Depending on the parameters of the game, this dynamic distortion captures either the crowdingout effect (when $I_{2}^{L^{\star}}>0$ ) or the durability effect (when $I_{2}^{L^{\star}}=0$ ).

It is straightforward to verify that $\Delta_{1}^{T}(\delta)$ is increasing in $\delta$. In other words, the smaller the depreciation of public good between periods, the larger are the total inefficiency. Since static inefficiencies do not change with $\delta$, this means that $\Delta_{1}^{D}(\delta)$ is also increasing in $\delta$. In other words, the stronger the link between periods (the smaller the depreciation rate) the bigger the portion of underprovision that come from the dynamic rather than the static nature of the bargaining. Furthermore, this comparative statics implies that the durability effect is always larger than the crowding-out effect, since as one increases the value of $\delta$ the dynamic inefficiencies increase and we shift from the region in which all dynamic inefficiencies are due to the crowding-out effect to the region in which all dynamic inefficiencies are due to the durability effect. 


\section{Experimental Design}

\subsection{Parameterization}

Our experimental design naturally requires the use of a specific parametric public investment function. In particular, we focus on the power function $u(g)=5 \sqrt{g}$. To create the simplest possible environment, which captures all the forces described in the previous section, we consider committees of 3 bargainers $(n=3)$ that meet for two consecutive periods. In each period, the committee needs to decide how to allocate a budget of 200 tokens between public good investment and pork to each member of the committee. We conduct all the experiments using the Baron-Ferejohn bargaining protocol described above and document participants' behavior in the legislative bargaining game. We then compare this behavior to the theoretical planner's solution to measure inefficiencies that arise from bargaining using the identification strategy described above.

We conduct three treatments, which differ only in the value of $\delta$, the survival rate of the public investment. The first treatment has $\delta=0$, and, thus, we refer to it as the static bargaining game and denote it by SB. The other two treatments are dynamic bargaining games, one with a low survival rate, $\delta=0.2\left(\mathrm{DB}^{\text {low }}\right)$, and one with high survival rate of $\delta=0.8\left(\mathrm{DB}^{\text {high }}\right){ }^{8}$ These two positive values of $\delta$ were chosen in a way that allows us to distinguish two types of dynamic inefficiencies: crowding-out and durability effects.

Table 1 displays the predicted values of public investment and private allocations in each period and in each treatment as a percentage of the budget. We also present theoretical values for static, dynamic and total inefficiencies using the planner solution.

When $\delta=0$, all period 1 inefficiencies are solely static (see the third column under the SB heading). In this case, the planner allocates an extra $15.5 \%$ of the budget to investment. When $\delta$ increases to 0.2 and we move to the $\mathrm{DB}^{\text {low }}$ game, dynamic inefficiencies emerge and total inefficiencies add up to $27.3 \%$ of the budget. In this case the dynamic inefficiencies are entirely due to crowdingout effect since $I_{2}^{L^{*}}>0$. In terms of magnitude, dynamic inefficiencies account for $11.8 \%$ of the budget and $43 \%$ of the total inefficiencies. The relative importance of dynamic inefficiencies changes dramatically when we further increase $\delta$ to 0.8 and move to the $\mathrm{DB}^{\text {high }}$ game. In this game dynamic inefficiencies are entirely due to the durability effect $\left(I_{2}^{L^{*}}=0\right)$ and they account for almost $40 \%$ of the budget as well as $72 \%$ of total inefficiencies. Although there are differences in magnitudes, dynamic inefficiencies represent a substantial and non-negligible amount of total inefficiencies in both $\mathrm{DB}^{\text {low }}$ and $\mathrm{DB}^{\text {high }}$ games.

We note that parameters of the game were chosen in a way that gives separation between theoretically predicted investment levels in period 1 in dynamic games $(44.9 \%$ versus $16.7 \%$ of the budget) and at the same time result in a similar average expected payment for subjects. The later property allows to controls for subjects' incentives between treatments, while the former property is important for interpreting the results of the experiments. The consequence of these parameter

\footnotetext{
${ }^{8}$ Recall that the survival rate of public investment is the inverse of the depreciation rate. That is, $\delta=0$ indicates full depreciation, $\delta=0.2$ indicates high depreciation, and $\delta=0.8$ indicates low depreciation rate.
} 
Table 1: Theoretical Outcomes as \% of Budget

\begin{tabular}{|c|c|c|c|c|c|c|c|c|c|c|c|c|c|}
\hline & \multicolumn{3}{|c|}{ SB } & \multicolumn{5}{|c|}{$\mathrm{DB}^{\text {low }}$} & \multicolumn{5}{|c|}{$\mathrm{DB}^{\text {high }}$} \\
\hline & $P^{*}$ & $L^{*}$ & $\Delta_{1}^{S}$ & $P^{*}$ & $L^{*}$ & $\Delta_{1}^{T}$ & $\Delta_{1}^{D}$ & $\frac{\Delta_{1}^{D}}{\Delta_{1}^{T}}$ & $P^{*}$ & $L^{*}$ & $\Delta_{1}^{T}$ & $\Delta_{1}^{D}$ & $\frac{\Delta_{1}^{D}}{\Delta_{1}^{T}}$ \\
\hline$\overline{I I}$ & 28.0 & 12.5 & 15.5 & 44.0 & 16.7 & 27.3 & 11.8 & $\bar{~} 0.43$ & 100 & 44.9 & 55.1 & 39.6 & 0.72 \\
\hline$X_{1}$ & 72.0 & 87.5 & & 56.0 & 83.3 & & & & 0.0 & 55.1 & & & \\
\hline$x_{1}^{\mathrm{Pr}}$ & & 58.4 & & & 55.6 & & & & & 36.8 & & & \\
\hline$x_{1}^{\mathrm{C}}$ & & 29.1 & & & 27.7 & & & & & 18.3 & & & \\
\hline$x_{1}^{\text {NonC }}$ & & 0.0 & & & 0.0 & & & & & 0.0 & & & \\
\hline$I_{2}$ & 28.0 & 12.5 & & 19.4 & 9.2 & & & & 0.0 & 0.0 & & & \\
\hline$X_{2}$ & 72.0 & 87.5 & & 80.6 & 90.8 & & & & 100 & 100 & & & \\
\hline$x_{2}^{\mathrm{Pr}}$ & & 58.4 & & & 60.5 & & & & & 66.7 & & & \\
\hline$x_{2}^{\mathrm{C}}$ & & 29.1 & & & 30.3 & & & & & 33.3 & & & \\
\hline$x_{2}^{\text {NonC }}$ & & 0.0 & & & 0.0 & & & & & 0.0 & & & \\
\hline
\end{tabular}

choices, however, is that total welfare (the sum of periods' 1 and 2 welfares) in the legislative bargaining equilibrium is almost identical in two dynamic treatments, $\mathrm{DB}^{\text {low }}$ and $\mathrm{DB}^{\text {high }}$. Hence, our main focus in this paper will be on period 1 investments.

\subsection{Experimental Interface and Procedures}

We conducted sessions at CASSEL (UCLA) and CESS (NYU) using Multistage software (see Table 2). ${ }^{9}$ In each location, subjects were recruited from the general undergraduate pool and each subject participated at most in one session. Sessions consisted of 12 or 15 participants. We refer the reader to the Appendix for the copy of the instructions that subjects received, the screen shots, the detailed script of the practice round and the quiz that was conducted to make sure subjects understand the structure of the game and the payoffs. ${ }^{10}$

Table 2: Subjects per treatment

\begin{tabular}{c|c|c|} 
Treatment & UCLA & NYU \\
\hline SB & $45(3$ sessions $)$ & \\
DB $B^{\text {low }}$ & $42(3$ sessions $)$ & \\
DB $^{\text {high }}$ & $30(2$ sessions $)$ & 24 (2 sessions $)$
\end{tabular}

In each session subjects played 10 repetitions of the two-period game and we refer to each repetition as a match. In each match subjects were randomly assigned to groups of three. We describe here the main features of the interface. To reduce the computational difficulties, subjects saw on the screen a graph that depicts how dollars (tokens) invested in the project are converted

\footnotetext{
${ }^{9}$ We find no significant differences in the behavior of subjects at NYU and at UCLA.

${ }^{10}$ This quiz consisted of 16 questions and subjects could only move forward once they answered all questions correctly. The quiz was conducted after the practice round and before the beginning of the paid rounds.
} 
into payoffs. ${ }^{11}$ At the beginning of each period, all subjects were asked to choose how they would distribute the available budget between private allocations and the public investment (referred to as the project investment in the instructions). The instructions emphasized how investment in period 1 can generate payoffs in period 2 for dynamic treatments. ${ }^{12}$ After all subjects in a group submitted their proposal, one of the three proposals was selected at random (with equal probability) and presented to all group members for a vote. If the proposal was accepted by a majority of votes (at least two out of three), then the period was over and the group moved on to the second period of the game, in which again all subjects were asked to submit their proposal and one of the proposals was chosen at random. If, however, the proposal was rejected, then the group remained in the first period and another bargaining stage started in which all members were asked to submit a new proposal. Throughout the experiment, subjects could follow the full history of the experiment in a box at the bottom of the screen. At the end of the session one match was selected at random for payment, earnings in that match were divided by 10 and the resulting figure plus the participation fee $(\$ 8)$ paid to participants in dollars. Average earnings were approximately $\$ 30$ and each session took about 2 hours.

\subsection{Experimental Hypotheses}

We use four main hypotheses to organize the experimental results. Our first hypothesis highlights the fundamental difference between dynamic and static bargaining games with respect to public investment in periods 1 and 2. While, naturally, public investment is expected to be the same in both periods in the static game, this is not the case in the dynamic game, in which period 1 public investment is predicted to be higher than period 2 public investment. We call this hypothesis the horizon effect hypothesis and summarize it as follows.

$$
\text { Horizon effect hypothesis: } I_{1}^{\mathrm{SB}}=I_{2}^{\mathrm{SB}} \text { and } I_{1}^{\mathrm{DB}}{ }^{\mathrm{j}}>I_{2}^{\mathrm{DB}} \text { for } j \in\{\text { high, low }\}
$$

The second hypothesis compares public good investment in period 1 across treatments and asserts that investment in the public good increases with the survival rate of the public good. We refer to this prediction as the investment hypothesis and note that it captures another essential feature of the dynamic game, namely that the benefit of investing in the first period is higher when the depreciation rate is lower.

$$
\text { Investment hypothesis: } I_{1}^{\mathrm{SB}}<I_{1}^{\mathrm{DB}}{ }^{\text {low }}<I_{1}^{\mathrm{DB}}{ }^{\text {high }}
$$

\footnotetext{
${ }^{11}$ Earlier pilot sessions were conducted with a different (less visual) interface. Those data are available upon request. Although the change to a more visual interface was motivated by our worry that the computational demands were high, there is no clear indication that this affected the results.

${ }^{12}$ The instructions included a table that explains for investment levels from 0 to 200 (in intervals of 10), how investment in period 1 will translate into period 2 payoffs (see Charness et al. (2004) for an example of the importance of payoff tables). Moreover, subjects were explicitly asked to go over this table when answering the quiz.
} 
The third hypothesis compares the magnitudes of under-provision across treatments, thus, the name under-provision hypothesis. In particular, the higher the survival rate $\delta$, the bigger the gap between the bargaining and the planner solution.

$$
\text { Under-provision hypothesis: } \quad 0<\left.\Delta_{1}^{T}\right|_{\mathrm{SB}}<\left.\Delta_{1}^{T}\right|_{\mathrm{DB}^{\text {low }}}<\left.\Delta_{1}^{T}\right|_{\mathrm{DB}^{\text {high }}}
$$

The fourth hypothesis compares the two sources of dynamic inefficiencies that are present in the dynamic treatments. We refer to this prediction as the dynamic inefficiency hypothesis and expect that the durability effect dominates the crowding-out effect.

$$
\text { Dynamic inefficiency hypothesis: } 0<\left.\Delta_{1}^{D}\right|_{\mathrm{DB}^{\text {low }}}<\left.\Delta_{1}^{D}\right|_{\mathrm{DB}^{\text {high }}}
$$

\section{Aggregate Results}

In this section we present results of our experiments focusing on the four hypothesis outlined in the previous section. In the next section (Section 5) we zoom in on the individual behavior of subjects to account for the variation that aggregate data abstract away from. Since the focus of this paper is on public provision in dynamic environments, most of the aggregate and individual results will concern public investments. We refer the reader to Appendix $\mathrm{C}$ in which we discuss other characteristics of the bargaining process such as the frequency of delays, the distribution of private allocations between committee members, and the determinants of voting behavior.

\subsection{Horizon Effect Hypothesis}

The two-period bargaining game analyzed in Section 2 is a relatively challenging environment. On the one hand, behavior in the two periods is interdependent and, on the other hand, behavior is predicted to be different across periods in all but the static treatment. We, therefore, start by assessing whether subjects internalize the fundamental difference between dynamic and static bargaining environments by comparing period 1 and period 2 public investments. According to the horizon effect hypothesis, period 2 public investment in both dynamic treatments is predicted to be smaller than period 1 public investment. This is true for both the efficient solution and the equilibrium bargaining solution as depicted in Table 1. The intuition for this result comes from the fact that while the utility of the public good is the same in both periods, the initial stock of the public good in period 2 is at least as high as the one in period 1 since $\delta>0$ and public investment in period 1 is non-negative. On the contrary, in the SB treatment, in which $\delta=0$, the public investment in both periods is expected to be the same.

Table 3 displays median investment levels per period in each treatment in the last 5 matches along with the theoretical predictions for efficient solution and that of the legislative bargaining equilibrium. ${ }^{13}$ As apparent from Table 3, our data supports the horizon effect hypothesis as public

\footnotetext{
${ }^{13}$ For the analysis from now on we restrict our attention to the stage in which a proposal was accepted. For the
} 
Table 3: Median Investment in each period as $\%$ of the Budget (last 5 matches)

\begin{tabular}{l|cc|cc|cc}
\hline \hline & \multicolumn{2}{|c|}{ SB } & \multicolumn{2}{c|}{ DB $^{\text {low }}$} & \multicolumn{2}{c}{ DB $^{\text {high }}$} \\
& Period 1 & Period 2 & Period 1 & Period 2 & Period 1 & Period 2 \\
\hline \multirow{2}{*}{ Planner's solution } & & & & & & \\
Legislative Bargaining equilibrium & 28.0 & 28.0 & 44.0 & 19.4 & 100.0 & 0.0 \\
Observed (all proposals) & 12.5 & 12.5 & 16.7 & 9.2 & 44.9 & 0.0 \\
\hline \hline
\end{tabular}

investment in period 2 is smaller than the one in period 1 in both dynamic treatments and is not different in the static treatment. This is confirmed by statistical tests. ${ }^{14}$ Notice also that the observed median public investment in both periods is significantly smaller than the efficient levels chosen by benevolent planner in all three treatments. The one exception is period 2 for the DB ${ }^{\text {high }}$ treatment in which the efficient solution predicts zero investment given that a large fraction of public investment from period 1 survived until period 2 . We note that qualitative results do not change when one looks at the average investment levels instead of the median ones or at all 10 matches of the experiment rather than the last 5 matches. ${ }^{15}$

Finding 1: Aggregate data supports the horizon effect hypothesis and indicates that subjects have a basic understanding of the dynamic tensions in the bargaining environment.

\subsection{Investment Hypothesis}

Table 4 presents the observed average and median investment in period 1 in the last 5 matches as well as the efficient and bargaining solutions. ${ }^{16}$ Observed investment is presented for two categories of proposals. The first category comprises all proposals submitted by all members of each group in the first stage of period 1 . The second category includes proposals that satisfy the minimum

stage in which a proposal was accepted we consider all proposals submitted by members of the committee. This means that for each match and each period we include in the analysis three proposals by committee, so that no particular period or match is given a higher weight. Because a large majority of first-stage proposals pass, the analysis is not qualitatively affected.

${ }^{14}$ To test for the difference in medians the unit of observation is each proposal per match. That is, for each subject and each match we keep track of the period 1 and period 2 investment proposals, and construct a variable that tracks the difference between period 1 and period 2 investment. We estimate the conditional median of the difference by performing a quantile regression, with the difference in investment on the left-hand side and a constant as a control. The estimated constant is not statistically different from zero in the static treatment, but significant at the $1 \%$ level for dynamic treatments. From now on we will use quantile regressions when we provide a test on the median. When we test for differences in means we use a random-effects panel regression with the variable of interest on the left-hand side and a control for the intended test on the right-hand side. In all our tests we cluster standard errors by session. In the text we will use the term 'statistically significant' when we can reject the null at $5 \%$.

${ }^{15}$ When we use mean values, findings are qualitatively unchanged. In the static treatment, the mean of the difference between period 1 and period 2 investment is relatively small (3.8\%), but it is statistically significant at the $5 \%$ level. In the bargaining treatments differences in investment across periods are also statistically significant, but much larger: 24.3 and $41.1 \%$ in the $\mathrm{DB}^{\text {low }}$ and $\mathrm{DB}^{\text {high }}$ cases respectively.

${ }^{16}$ We discuss the evolution of sessions in Appendix C. 
winning coalition (MWC) condition, which are defined as proposals in which $\frac{n-1}{2}$ members of the committee receive a private allocation of no more than $10 \%$ of the budget and $\frac{n+1}{2}$ members receive strictly more than $10 \%$ of the budget in private allocations. ${ }^{17}$ The subset of proposals that were randomly chosen to be voted on and received a majority of votes looks very similar to the first category of all proposals and, therefore, omitted for brevity. ${ }^{18}$

Table 4: Investment in Period 1 as \% of Budget (last 5 matches)

\begin{tabular}{|c|c|c|c|c|c|c|c|c|c|}
\hline & \multicolumn{3}{|c|}{ SB } & \multicolumn{3}{|c|}{$\mathrm{DB}^{\text {low }}$} & \multicolumn{3}{|c|}{$\mathrm{DB}^{\text {high }}$} \\
\hline & mean & median & st. err. & mean & median & st. err. & mean & median & st. err. \\
\hline Planner's solution & \multicolumn{2}{|c|}{28.0} & & \multicolumn{2}{|c|}{44.0} & & \multicolumn{2}{|c|}{100.0} & \\
\hline Bargaining solution & \multicolumn{2}{|c|}{12.5} & & \multicolumn{2}{|c|}{16.7} & & \multicolumn{2}{|c|}{44.9} & \\
\hline (a) all proposals & 16.7 & 10.0 & 13.4 & 38.7 & 31.8 & 31.9 & 55.2 & 55.0 & 32.7 \\
\hline (b) MWC proposals & 11.1 & 10.0 & 7.3 & 18.3 & 10.0 & 20.3 & 29.3 & 25.0 & 20.1 \\
\hline
\end{tabular}

To test the investment hypotheses outlined above, we decompose it into three pairwise comparisons and test each separately: $I_{1}^{\mathrm{SB}}<I_{1}^{\mathrm{DB}}{ }^{\text {low }}, I_{1}^{\mathrm{SB}}<I_{1}^{\mathrm{DB}}{ }^{\text {high }}$ and $I_{1}^{\mathrm{DB}}{ }^{\text {low }}<I_{1}^{\mathrm{DB}}{ }^{\text {high }}$. Furthermore, we test these three inequalities for two categories of proposals (a) and (b) separately, where we take the proposal of a subject as the unit of observation. For category (a) we take all proposals, while for category (b) we take only those proposals that satisfy the MWC requirement. To test differences in the mean, we run a random effects regression that uses the quantity of interest on the left-hand side and varies the right-hand side depending on the specific test. For instance, to test whether public investment in period 1 is higher in the $D B^{\text {low }}$ than in the $S B$ treatment, the right-hand side includes the constant and a dummy variable that takes value 1 if the proposal is from $D B^{\text {low }}$. We always cluster standard errors by session. ${ }^{19}$

Our analysis reveals that public investment monotonically increases with the survival rate $\delta$ irrespectively of whether one focuses on all submitted proposals or proposals that satisfy MWC condition. This effect is significant at $5 \%$ level in all the pairwise comparisons. In addition, investment levels are generally higher in all proposals than in the MWC proposals.

Finding 2: Investment in the public good increases with the survival rate of the public good as predicted by the investment hypothesis.

\footnotetext{
${ }^{17}$ Note that the definition of MWC suggests that different members of committees are treated differently with respect to their private allocations: some are included in the coalition while others are not. Thus, proposals that involve investing the whole budget in the public investment, and, therefore, treat all members equally, do not satisfy the MWC condition. Allowing non-coalition partners to receive small shares is standard in the literature.

${ }^{18}$ Consistent with the previous literature, we find that a majority of proposals are passed without delay in all three treatments and in both periods of the game. These results are presented in Appendix C.

${ }^{19}$ To test differences in medians we use quantile regressions. Our results do not not change if we used all matches or constrain the analysis to the last 5 matches.
} 


\subsection{Under-provision Hypothesis}

Table 5 presents predicted and observed distortions in period one public investment as well as its decomposition into the static and dynamic components. We use this information to examine the under-provision hypothesis, according to which the total inefficiencies in period 1 public provision monotonically increase with the survival rate of the public good.

Table 5: Total and Dynamic Inefficiencies (as \% of Budget)

\begin{tabular}{|c|c|c|c|c|c|c|c|c|c|c|c|c|c|}
\hline \multirow[b]{2}{*}{ Investment in Period 1} & \multicolumn{3}{|c|}{ SB } & \multicolumn{5}{|c|}{$\mathrm{DB}^{\text {low }}$} & \multicolumn{5}{|c|}{$\mathrm{DB}^{\text {high }}$} \\
\hline & Planner & Barg & $\Delta_{1}^{S}$ & Planner & Barg & $\Delta_{1}^{T}$ & $\Delta_{1}^{D}$ & $\frac{\Delta_{1}^{D}}{\Delta_{1}^{T}}$ & Planner & Barg & $\Delta_{1}^{T}$ & $\Delta_{1}^{D}$ & $\frac{\Delta_{1}^{D}}{\Delta_{1}^{T}}$ \\
\hline Theory & 28.0 & 12.5 & 15.5 & 44.0 & 16.7 & 27.3 & 11.8 & 0.43 & 100 & 44.9 & 55.1 & 39.6 & 0.72 \\
\hline (a) all proposals & & 16.7 & 11.3 & & 38.7 & 5.3 & -6.0 & - & & 55.2 & 44.8 & 33.5 & 0.75 \\
\hline (c) MWC proposals & & 11.1 & 16.9 & & 18.3 & 25.7 & 8.8 & 0.34 & & 29.3 & 70.7 & 53.8 & 0.76 \\
\hline
\end{tabular}

Planner: Planner's solution, Barg: Legislative Bargaining solution

$\Delta_{1}^{S}$ : Static Inefficiencies, $\Delta_{1}^{D}$ : Dynamic Inefficiencies, $\Delta_{1}^{T}$ : Total Inefficiencies

Observed $\Delta_{1}^{S}, \Delta_{1}^{T}$ computed using theoretical values for the planner's problem.

In each category (a), (b) and (c) we use mean investment in the last five matches

Table 5 shows that the estimated magnitudes of distortions are sensitive to the category of proposals one focuses on. If we constrain proposals to those involving MWCs (category (b)), then we find support for the under-provision hypothesis. In other words, proposals that satisfy the MWC condition exhibit the following pattern: the total amount of under-provision in these proposals relative to the efficient solution increases with the survival rate of the public good and this increase is statistically significant between any two pairs of treatments at the $5 \%$ level. ${ }^{20}$

However, the picture is different if one looks at all submitted proposals. For this category, the under-provision hypothesis holds only partially. The total amount of inefficiency is significantly higher in the $D B^{\text {high }}$ treatment than in either the static $S B$ treatment or the dynamic $D B^{\text {low }}$ treatment at the $5 \%$ level. However, we do not observe a significant change in the total inefficiencies when moving from $\delta=0$ to $\delta=0.2$, which corresponds to $S B$ and $D B^{\text {low }}$ treatments respectively.

Finding 3: Consistent with the hypothesis, public good under-provision in the $D B^{\text {high }}$ treatment is higher than in the $S B$ and $D B^{\text {low }}$ treatments. Under-provision is statistically higher in $D B^{\text {low }}$ than in the $S B$ treatment for $M W C$ proposals.

\subsection{Dynamic Inefficiency Hypothesis}

Our last hypothesis investigates the presence and relative magnitude of the dynamic inefficiencies in $D B^{\text {low }}$ and $D B^{\text {high }}$ treatments. To statistically examine the presence of dynamic inefficiencies we run a random effects regression for each DB treat ment with period 1 investment on the left-hand

\footnotetext{
${ }^{20}$ We use the same statistical analysis as one described in Section 3.2. That, is we use a random-effects panel regression to test differences in mean $\Delta_{1}^{T}$ and quantile regression analysis to test differences in median $\Delta_{1}^{T}$.
} 
side. In the $\mathrm{DB}^{\text {high }}$ case, the right-hand side variables are a constant and a dummy that takes value 1 if the proposal corresponds to the $\mathrm{DB}^{\text {high }}$ treatment and 0 if it corresponds to SB. We then contrast the estimated coefficient with the theoretical increase in the planner's investment relative to the SB case, which equals $72 \%(100 \%-28 \%)$. The estimated coefficient on the dummy using all proposals is $38.5 \%$ (19.2\% using proposals that satisfy the MWC condition), which is significantly less than $72 \%$ at the $1 \%$ level (using either all submitted or all MWC proposals). Thus, there is evidence of dynamic inefficiencies in the $\mathrm{DB}^{\text {high }}$ treatment. In a similar analysis of the $\mathrm{DB}^{\text {low }}$ treatment, the estimated coefficient implies that investment in the $\mathrm{DB}^{\text {low }}$ treatment is $22 \%$ higher than in the $\mathrm{SB}$ if we use all proposals (7.6\% if we only use MWC proposals). The theoretical increase in the planner's investment is $16 \%(44 \%-28 \%)$. Therefore, for the $\mathrm{DB}^{\text {low }}$ treatment, we find a statistically significant difference for MWC proposals. Finally, when comparing the two dynamic treatments, we find that the dynamic inefficiencies are significantly greater in the $\mathrm{DB}^{\text {high }}$ treatment than in the $\mathrm{DB}^{\text {low }}$ treatment. This follows from the difference in total inefficiencies between the two treatments reported earlier. ${ }^{21}$

Finding 4: Dynamic inefficiencies are significant and large in magnitude in the DB ${ }^{\text {high }}$ treatment, and significantly greater than in the DB low treatment, irrespectively of whether one focuses on all submitted or MWC proposals. These findings provide support for the dynamic inefficiency hypothesis. However, we observe significant dynamic inefficiencies in the DB low treatment only for MWC proposals.

\section{Individual Data Analysis}

Our previous results considered aggregate level data. These results suggest relatively high degree of heterogeneity in public investment decisions across subjects (see, for example, the standard errors reported in Table 3). In this section we look at the individual level data with the aim of documenting and studying in more depth the main types of strategies used by our subjects. This section is structured as follows. First, we define three types of strategies and show that these types capture the vast majority of the observed public investments. Then we document the popularity of each type of strategy and look at their prevalence as the sessions evolve. Second, for each type of strategy we compare public investments in both periods to the optimal investments conditional on the type of strategy used. Third, we consider payoffs associated with the use of each type of strategy and study whether these payoff differences can account for the differences in the use of the strategies between treatments. Finally, we provide some insights into the rationale for the observed strategies.

\footnotetext{
${ }^{21}$ The conclusions are the same if we focus on median investment instead.
} 


\subsection{Types of strategies and evolution of their use}

A strategy in our two period dynamic game is a proposal in period 1, and a period 2 proposal for each of period 1's possible outcomes. In our data we partially observe period 2 choices, as we learn each subject's period 2 proposal only for the proposal that passed in period 1 . In this section, the unit of observation will be the subject's choice in both periods of the match and, even though this is an abuse of terminology, we will refer to it as the subject's strategy. There are three types of strategies that account for the vast majority of observed choices:

- MM strategies

Involve forming MWCs in both periods, where MWC proposals are defined as above.

- EE strategies

Involve splitting benefits equally between all three members in both periods, where we define as an equal split any proposal in which the difference in private allocations between any two members is not larger than 5 tokens ( $2.5 \%$ of the budget). ${ }^{22}$

- EM strategies

Involve splitting resources equally in period 1 and forming MWC in period 2.

Figure 1 plots the proportion of subjects who submit a proposal of each identified strategy type by match in each treatment. The first observation is that classifying proposals into the three strategy types outlined above accounts for the vast majority of all observed choices: $88 \%$ in SB game and $94 \%$ in either of the DB games in the last 5 matches (see also the dotted line that represents the total number of observations that fall into one of the defined types).

The popularity of each strategy type varies with the treatment and evolves as subjects gain experience with the environment. However, in all three treatments, the EE strategy looses its popularity to MM and EM strategies as session evolves. Indeed while EE type strategies are the most common in all treatments at the beginning of the session, there is a clear decline in their use by the end of the session especially in the SB and the DB ${ }^{\text {high }}$ treatments. ${ }^{23}$ The two other types of strategies gain popularity as subjects gain experience. In the SB game, by the end of the session almost $70 \%$ of all strategies are of type MM, while in the DB treatments, about one-third of all proposals are of type MM. Type EM strategies are relatively more popular in the DB treatments, accounting for $30 \%-40 \%$ of all proposals in the last five matches. ${ }^{24}$

\footnotetext{
${ }^{22}$ Formally, let $x_{i t}$ represent the share of the budget corresponding to a private allocation to subject $i$ at period $t$ according to some proposal. We say that proposal at time $t$ splits equally benefits (or that all members are included in the proposal) if $\left|x_{i t}-x_{j t}\right| \leq 2.5 \%$ for all $i, j$ in the committee. The reason that we allow for small deviations from the exact equal splits is that the total budget of 200 is not divisible by three.

${ }^{23}$ The decline in popularity of the EE strategy over time is reminiscent of: 1) In Fréchette et al. (2003) the authors observe that distributions offering an equal division of payoffs decreases in popularity with experience. 2) In VCM experiments, contributions decline with experience, i.e. outcomes become less efficient over time.

${ }^{24}$ The analysis of the transitions between strategies reveals that subjects that play MM strategies in the static treatment and $\mathrm{MM}$ or $\mathrm{EM}$ strategies in the $\mathrm{DB}^{\text {high }}$ treatment are very likely to stick with this type of strategy. Conditional on changing the type of strategy used, the most popular transitions are from EM to MM type of strategies and from EE to EM type of strategy. The detailed analysis of the transitions between strategies is presented in Appendix D.
} 

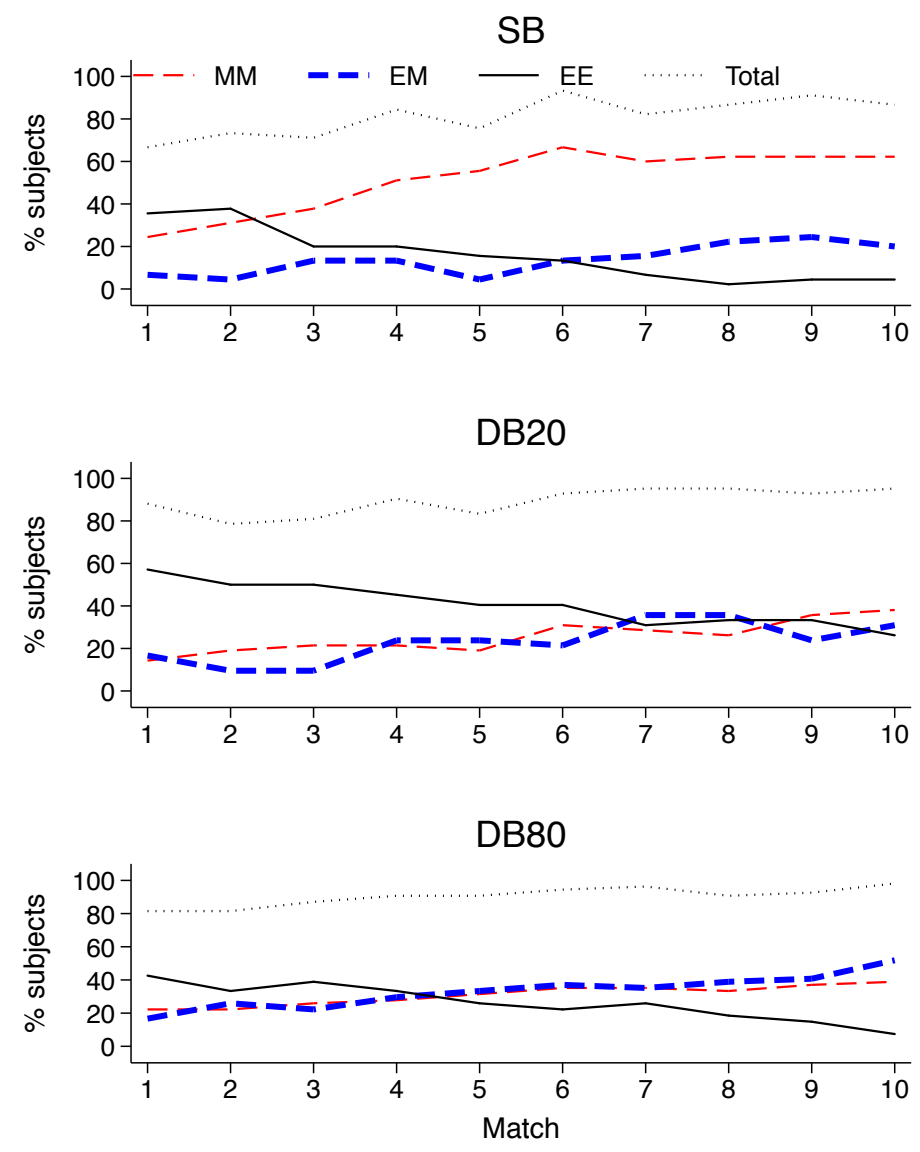

Figure 1: The evolution of strategies used by subjects in each treatment 
Table 6: Investment as \% of Budget

\begin{tabular}{|c|c|c|c|c|c|c|c|c|c|c|c|c|}
\hline \multirow{2}{*}{ Treatment } & \multicolumn{4}{|c|}{ Type MM } & \multicolumn{4}{|c|}{ Type EM } & \multicolumn{4}{|c|}{ Type EE } \\
\hline & theory & mean & median & sd & theory & mean & median & sd & theory & mean & median & sd \\
\hline \multicolumn{13}{|l|}{ Period 1} \\
\hline SB & 12.5 & 12.8 & 10.0 & 9.1 & 28.0 & 27.5 & 25.0 & 11.0 & 28.0 & 31.0 & 25.0 & 13.6 \\
\hline $\mathrm{DB}^{\text {low }}$ & 16.7 & 17.9 & 10.0 & 20.7 & 44.0 & 56.8 & 50.0 & 34.9 & 44.0 & 49.6 & 40.0 & 30.6 \\
\hline $\mathrm{DB}^{\text {high }}$ & 44.9 & 33.2 & 30.0 & 19.6 & 100 & 75.5 & 85.0 & 28.5 & 100 & 70.6 & 70.0 & 28.8 \\
\hline \multicolumn{13}{|l|}{ Period 2} \\
\hline $\mathrm{SB}$ & 12.5 & 11.9 & 10.0 & 8.6 & 12.5 & 12.7 & 10.0 & 13.4 & 28.1 & 30.5 & 25.0 & 23.6 \\
\hline $\mathrm{DB}^{\text {low }}$ & 9.2 & 8.7 & 0.0 & 15.3 & 9.2 & 6.8 & 0.0 & 13.0 & 19.3 & 32.0 & 25.0 & 29.9 \\
\hline $\mathrm{DB}^{\text {high }}$ & 0.0 & 13.2 & 5.0 & 18.0 & 0.0 & 7.4 & 0.0 & 15.7 & 0.0 & 44.4 & 29.5 & 31.5 \\
\hline
\end{tabular}

\subsection{Behavior within each strategy type}

Each of the three types of strategies identified above entails very different public investment and allows, in principle, for heterogeneous behavior within the category. For example, for the MM strategy, infinitely many proposals satisfy the MWC condition in both periods, yet of all such proposals the bargaining equilibrium identifies one as optimal behavior given imposed restrictions of symmetry, stationarity and anonymity between periods. Similarly, conditional on using the EE strategy, the optimal behavior involves choosing the efficient level of public investment and distributing the remaining funds equally. ${ }^{25}$ Finally, the EM strategy combines elements of the bargaining equilibrium and the efficient planner's solution. Thus, conditional on using the EM strategy, optimal behavior involves choosing public provision at the efficient level in period 1 and following the prescription of bargaining equilibrium for public provision in period 2.

Given the prevalence of all three types of strategies in our data, the first natural question is whether, conditional on using a particular type of strategy, subjects choose investment levels that are close to the theoretical ones described above. To address this we calculate the theoretically optimal proposals within each category and compare it to the observed proposals conditional on the type of strategy used. The results are presented in Table 6.

Table 6 reveals several interesting patterns. First, investment levels are very different between proposals of different types. In particular, subjects using EM or EE type of strategies invest significantly higher share of resources in the public good in period 1 than those that use MM strategies. ${ }^{26}$ Moreover, within each category, public investment in period 1 preserves a monotonic relation with respect to the survival rate $\delta$, that is, public provision increases with the survival rate. ${ }^{27}$ Finally, in

\footnotetext{
${ }^{25}$ Notice that the use of the EE strategy cannot be supported as the sub-game perfect equilibrium in finite period dynamic bargaining game, as treating committee members equally in the last period is not optimal.

${ }^{26}$ If we use a random effects tobit model to acknowledge the fact that the theoretical value is at the boundary, then the Type EM proposal is not significantly different from the prediction. All other statistical statements remain unchanged.

${ }^{27}$ Within each category, the difference is significant at least at the $5 \%$ level in all but two cases. For proposals of type $\mathrm{EE}$ when comparing between the $\mathrm{DB}^{\text {low }}$ and the $\mathrm{DB}^{\text {high }}$ treatments and for proposals of type MM when
} 
$\mathrm{SB}$ and $\mathrm{DB}^{\text {low }}$ treatments, for each of the three types of strategies, public investments tracks closely theoretically optimal levels in both periods. On the contrary, in $\mathrm{DB}^{\text {high }}$ treatment, we observe under provision of public good in period 1 and over provision of public good in period 2 relative to the conditional optimal levels, irrespectively of the type of strategy used by the subjects. ${ }^{28}$ Notice that in the $\mathrm{DB}^{\text {high }}$ treatment in all but one case the conditionally optimal public investment is a corner solution (the exception is optimal period 1 public provision for MM strategy). Therefore, any deviations due to mistakes and learning will necessarily be in the direction of underinvesting in period 1 and over-investing in period 2, which is precisely what our data suggests.

\subsection{Payoffs for each type of strategy}

Table 7 displays information on payoffs by treatment, period and strategy type. For each proposal we compute the payoff for the proposer, for a non-proposer who is in the coalition and for a member who is not in the coalition, whenever the proposal involves a MWC. The table reports the theoretical prediction, the mean and the median using data from the last five matches.

The information on payoffs suggests why the popularity of type EE strategies decreases as the session evolves. Note that period 2 payoffs for proposers are lowest for those submitting type EE strategies, and experiencing low period 2 payoffs can disincentive using this strategy type. Indeed Table 11 in Appendix D confirms that a large majority of subjects who are using type EE strategies by match 6 switch to either of the other two characterized strategy types for the last 4 matches of the session.

Inspecting payoffs also provides a rationale for why both, type MM and type EM strategies, persist. We do observe some differences in payoffs across these two strategy types: Payoffs for type MM strategies are higher for those in the coalition, while type EM strategies allow for higher period 2 payoffs given the relatively higher investment in period 1 (most notably in the $\mathrm{DB}^{\text {high }}$ treatment). However, differences between strategies are small if we compute total payoffs, adding period 1 and period 2. Consider the $\mathrm{DB}^{\text {high }}$ treatment. The payoff of a type MM strategy is 190 tokens (before the identity of the proposer is revealed), which is only slightly below the 193 tokens corresponding to a type EM. Thus, for the two strategy types that corresponds to most of our data in later matches, the difference in payoffs is relatively small. ${ }^{29}$ This suggests that the choice between type MM and type EM strategies is not based on a difference in payoffs. In the next section we explore a rationale for selecting type EM strategies.

comparing between SB and the $\mathrm{DB}^{\text {low }}$ treatments the difference is significant at the $10 \%$ level.

${ }^{28}$ Standard deviations reported in Table 6 indicate that there is some heterogeneity between subjects using the same type of strategy. Figure 6 in the Appendix D provides a closer look at the investment distributions for proposals of type MM and EM. The SB treatment represents the most accurate case, with the mode of the distribution at around the theoretical prediction for both MM and EM strategies. In the DB treatments, there is more heterogeneity for both types of proposals.

${ }^{29}$ In Table 13 of Appendix D we explore this comparison further. 
Table 7: Payoffs in tokens (last 5 matches-all submitted proposals)

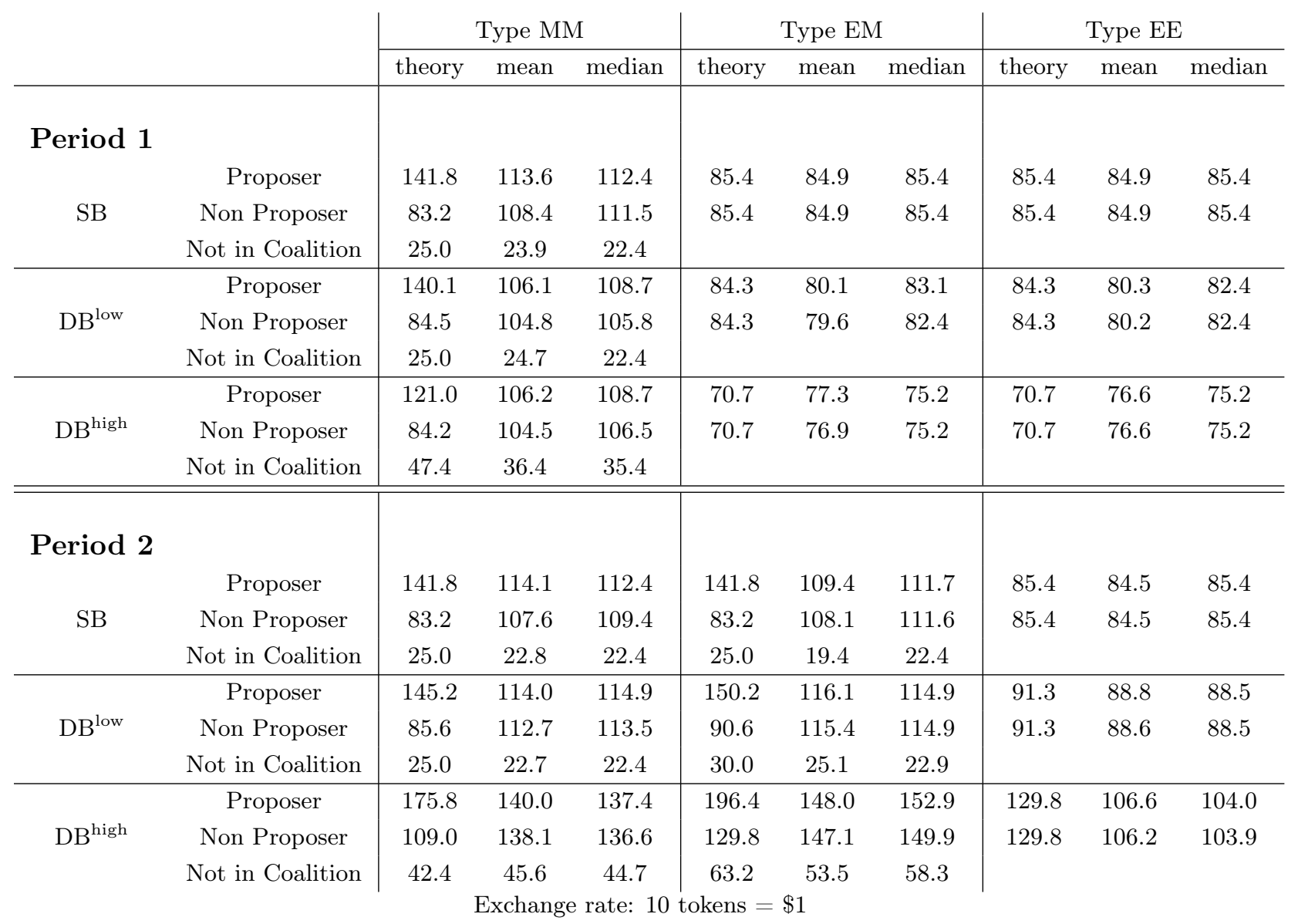




\subsection{A rationale for type EM strategies}

Consider an EM strategy that involves public investment at the planner's level in period 1 and dividing equally the remainder. In period 2 the proposer behaves just as in the bargaining equilibrium (forms a MWC and invests in the pubic good optimally given period 1 investment) except for the choice of the coalition partners. If period 1's proposer provided an amount of public good at the efficient level, then the proposer in period 2 invites period 1's proposer into the coalition in period 2. Otherwise, the period 2 proposer punishes period 1's proposer by excluding her from the coalition in period 2. Such a strategy can be implemented in our experiment, since the ID numbers of the committee members remain the same within a match. Theoretically, however, such a strategy cannot be supported as a sub-game perfect equilibrium, since the rewards and punishments are not credible. In the period 2 subgame, after a period 1 proposer deviated from cooperation (efficient investment in period 1), any other committee member should exclude her from the coalition. Because she is not included in coalitions proposers by others, the punished agent's continuation value is the lowest of all agents. Thus, any proposer is tempted to deviate, pay her less than the alternative, and include her in the coalition.

To see whether the described punishments/rewards mechanism is consistent with the behavior of subjects that opted to use the EM strategy, we focus on period 2 proposals from subjects who were not proposers in period 1. Let $x_{2}^{P 1}$ be the private allocation in period 2 to a subject who was the proposer in period 1 (P1). The dummy variable $A 1$ takes value 1 if the period 1 proposer proposed an allocation that benefits equally all three members and 0 otherwise (see Section 3.3). A period 2 proposer that uses EM strategy punishes period 1 proposer by allocating her $x_{2}^{P 1}=0$ whenever $A 1=0$ and rewards her by $x_{2}^{P 1}>0$ whenever $A 1=1$. Therefore, we would expect $E\left(x_{2}^{P 1} \mid A 1=0\right)<E\left(x_{2}^{P 1} \mid A 1=1\right)$. Contrarily, we would expect to observe no such difference for other types. We will test for this hypothesis by estimating for each treatment:

$$
x_{2}^{P 1}=\alpha_{0}+\alpha_{1} \cdot A 1+\alpha_{2} \cdot E M_{\text {strategy }}+\alpha_{3} \cdot\left(A 1 \times E M_{\text {strategy }}\right)+\epsilon,
$$

where $\epsilon \sim N(0, \sigma)$ and $E M_{\text {strategy }}$ is a dummy variable that takes value 1 if the proposal involving $x_{2}^{P 1}$ is of Type EM. We estimate a random effects regression for each treatment separately and report in Table 8 the average private allocations to period 1 proposers depending on their period 1 behavior $(A 1)$ and the type of the proposal in period $2 .{ }^{30}$ Notice that for proposals that are not of EM type $\left(E M_{\text {strategy }}=0\right)$ there is no quantitative difference between proposers who cooperated $(A 1=1)$ and those who did not $(A 1=0)$. The difference is dictated by the estimates of $\alpha_{2}$, which are not significant for $D B$ treatments and, although significant, it is relatively small in the $S B$ case. This is no longer the case for Type EM proposals. Differences are significant in the $D B$ treatments, but of similar magnitude in all cases, between $10 \%$ and $15 \%$ of the budget approximately.

The previous evidence shows that subjects using EM strategies offer lower payoffs to period 1 proposers who deviated from cooperation, but they still offer a positive amount on average while

\footnotetext{
${ }^{30}$ The estimated coefficients from equation above are reported in Table 14 of Appendix D.
} 
Table 8: Punishments: Private allocation to period 1 proposer $\left(x_{2}^{P 1}\right)$

\begin{tabular}{l|c||c|c|c} 
Strategy type & Period 1 Proposer & $S B$ & $D B^{\text {low }}$ & $D B^{\text {high }}$ \\
\hline \multirow{2}{*}{$E M_{\text {strategy }}=1$} & $A 1=1$ & 21.66 & 27.78 & 29.05 \\
& $A 1=0$ & 14.14 & 10.45 & 19.55 \\
\hline \multirow{2}{*}{$E M_{\text {strategy }}=0$} & $A 1=1$ & 23.10 & 21.31 & 19.70 \\
& $A 1=0$ & 20.50 & 19.52 & 22.29
\end{tabular}

the theory predicts a payoff of zero. To inspect this further Figure 2 presents the distribution of $x_{2}^{P 1}$ for $D B$ treatments. Consider the top left graphs summarizing the information for EM strategies in the $D B^{\text {low }}$ treatment. When the proposer did not cooperate in period $1(A 1=0)$ the mode involves zero private allocations. Contrarily, investment at the planner's optimum in period $1(A 1=1)$ shows a large mass with positive private allocations. The same qualitative finding holds for EM proposals in the $D B^{\text {high }}$ treatment. This patterns are no longer observed if, for example, we focus on MM proposals (second row). The mass of zero offers does not show large differences depending on the behavior of period 1's proposer.

\section{Conclusion}

When there are dynamic linkages in the intertemporal provision of a durable public good the usual static inefficiencies are present, but new dynamic inefficiencies arise. Since introducing a dynamic link in a model is typically more theoretically demanding, a prominent question is whether such inefficiencies are empirically meaningful. In this paper, we design an experiment that can isolate static and dynamic inefficiencies in a two-period laboratory environment, and report the findings of that experiment.

When the theory predicts dynamic inefficiencies to be large, the data are in line with the prediction. Our data indicate that subjects respond to the incentives in the environment in similar ways to earlier experiments on legislative bargaining. With experience, bargaining delays become infrequent and minimum winning coalition proposals become more prevalent. The main focus of our analysis is on period 1 investment behavior, because that is key to identifying dynamic inefficiencies and measuring the extent to which they affect outcomes. On average, investment in the first period is highest when the proportion of period 1 investment that survives in period 2 is high, i.e, the depreciation rate of the durable public good is low. Moreover, period 1 investment is monotonically lower as the depreciation rate increases. Accordingly, when dynamic linkages are relatively low, dynamic inefficiencies become less important, as predicted by the theory. Overall our data indicates that dynamic inefficiencies can be empirically quite large, especially when depreciation rates are low.

We also document heterogeneity in individual behavior. Some subjects propose investment levels that are close to the planner's in both periods, especially in early matches. While those subjects may be driven by altruism, the prevalence of this behavior is substantially reduced as the session evolves. In later matches we are able to identify two canonical types of behavior that capture most of the 
Type EM in DB low
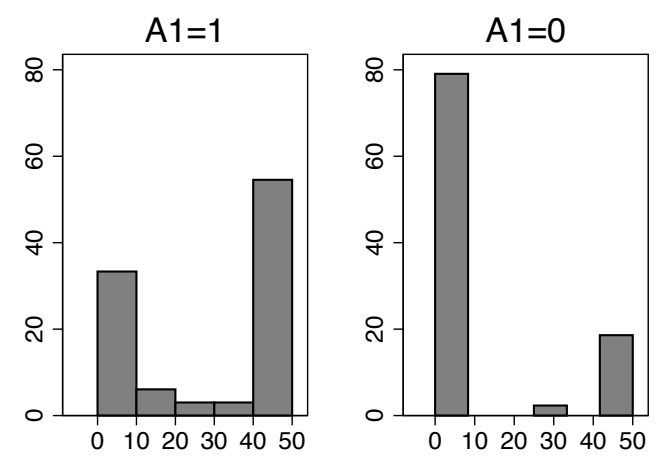

Type MM in DB low
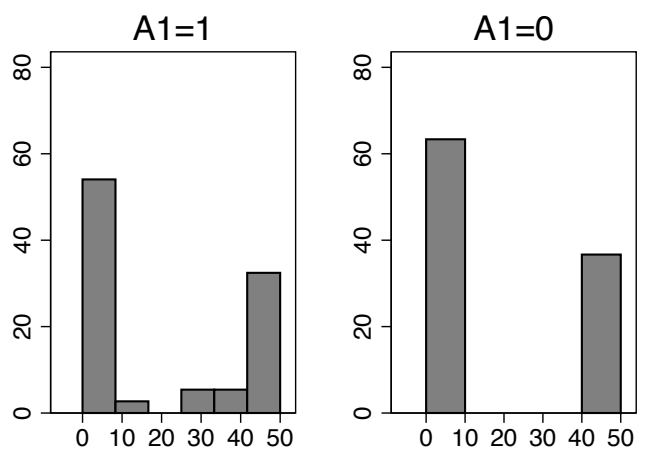

Type EM in DB high
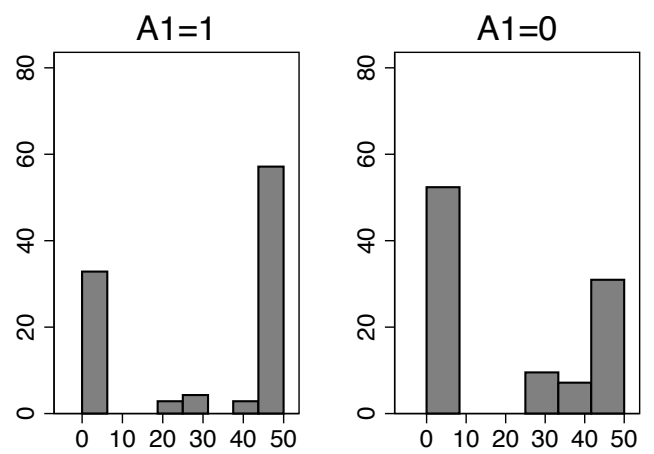

Type MM in DB high

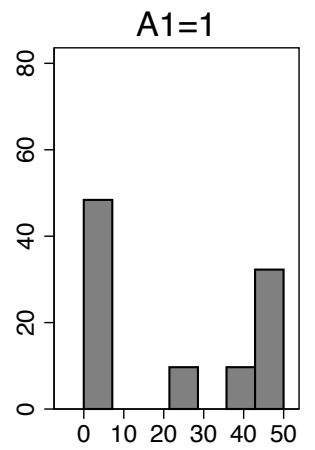

Figure 2: Distribution of Private period 2 allocations to period 1 proposers as $\%$ of Budget (Not) All included: Period 1 proposal (does not) includes all members

Note: This Figure includes period 2 proposals from subjects who were not proposers in period 1 
data. First, a large proportion of subjects use strategies that involve minimum winning coalitions and display investment levels that are, on average, close to the theoretical predictions. The second prevalent behavior involves strategic cooperation. These are subjects whose proposals in the first period are significantly higher than the theoretical level, and then use a minimum winning coalition in period 2 to reward/punish period 1 choices. According to such behavior, if the investment level proposed in period 1 was efficient (or nearly efficient), then the committee member who made that proposal would be invited into the coalition in period 2 and excluded otherwise. While this behavior is not sub-game perfect, average payoffs are quite close to those who always proposed a minimum winning coalition. This behavior is suggestive that a non non-negligible fraction of subjects condition period 2 behavior on period 1 outcomes.

We close with two comments about the two-period approach we use to study dynamic free riding. First, while much of the theory about the dynamic provision of durable public goods has been studied using infinite horizon models, the basic phenomenon of dynamic free riding appears even in simple finite horizon models with two periods of public good accumulation. This allows for much simpler experimental designs, compared with experiments that are designed to mimic an infinite horizon using random termination rules. Methodologically, it allows for a more straightforward analysis of the data, which always appear in blocks of two periods, rather than the data from experiments with random termination rules, where different observations have different numbers of periods. On the other hand, the two period models lack the elegance of the infinite horizon models and cannot address deeper theoretical issues about convergence to stationary states (public good levels) and Markov equilibrium. The philosophy behind our design is that this tradeoff probably favors the two-period model if the goal of the experiment is to compare treatments aimed at sorting out and identifying static and dynamic free riding effects. In other contexts, where the goal is to evaluate outcomes relative the predicted long run steady states or to test for Markov equilibrium, the tradeoff tilts the other way, and there are several examples of this. See, for example Battaglini and Palfrey (2012), Battaglini et al. (2012), Vespa (2014), and Battaglini et al. (2013).

Second, there are other dynamic environments that have been modeled theoretically using infinite horizon stochastic games, which may also merit study in the laboratory using a two-period approach. An example of this is the experimental study Battaglini et al. (2014b) of a simple two period version of the Battaglini-Coate infinite horizon model of the political economy of debt and public good provision Battaglini and Coate (2008).

The study of dynamic games in the lab is still relatively new. Although questions having to do with public goods or legislative bargaining have a long history in experimental economics, how what we have learned up to this point translates to dynamic enviornments is not self-evident. We think that a richer and more nuanced understanding of the impact of dynamic linkages on these environments can be obtained by both studying infinitely repeated games as well as simpler games that allow to better focus on certain features of the dynamic enviornment. In the context of legistlative bargaining with durable public goods we show that indeed subjects react to the tensions identidied by the model, in particular both the force of static and dyanmic free-ridding. However, 
we also find that many subjects deviate from the equilibirum strategy in favor of an efficient strategy with an easy to implement punishment.

\section{References}

Baron, David P. and John A. Ferejohn, "Bargaining in Legislatures," American Political Science Review, December 1989, 83 (4), 1181-1206.

Battaglini, M. and S. Coate, "A Dynamic Theory of Public Spending, Taxation, and Debt," The American Economic Review, 2008, 98 (1), 201-236.

- and T.R. Palfrey, "The Dynamics of Distributive Politics," Economic Theory, 2012, 49 (3), 739-777.

_, S. Nunnari, and T. Palfrey, "The Dynamic Free Rider Problem: A Laboratory Study," Caltech Social Science Working Paper 1371, 2013.

_ , _ and _ , "Dynamic Free Riding with Irreversible Investments," American Economic Review, 2014, 104 (9), 2858-2871.

_ , _ , and _ , "The Political Economy of Pubic Debt: A Laboratory Study," working paper, in preparation, 2014.

_ , _, and T.R. Palfrey, "Legislative Bargaining and the Dynamics of Public Investment," American Political Science Review, 2012, 106 (2), 407-429.

Charness, Gary, Guillaume R Fréchette, and John H Kagel, "How robust is laboratory gift exchange?," Experimental Economics, 2004, 7 (2), 189-205.

Fréchette, G.R., J.H. Kagel, and M. Morelli, "Behavioral identification in coalitional bargaining: An experimental analysis of demand bargaining and alternating offers," Econometrica, 2005, 73 (6), 1893-1937.

Fréchette, G.R., J.H. Kagel, and M. Morelli, "Pork versus public goods: an experimental study of public good provision within a legislative bargaining framework," Economic Theory, 2012, pp. 1-22.

Fréchette, G.R., J.H. Kagel, and S.F. Lehrer, "Bargaining in legislatures: An experimental investigation of open versus closed amendment rules," American Political Science Review, 2003, 97 (02), 221-232.

Herr, A., R. Gardner, and J.M. Walker, "An Experimental Study of Time-Independent and Time-Dependent Externalities in the Commons* 1,*2," Games and Economic Behavior, 1997, 19 (1), 77-96. 
Ledyard, John O., Handbook of Experimental Economics, Princeton: Princeton University Press,

Lei, V. and C.N. Noussair, "An experimental test of an optimal growth model," American Economic Review, 2002, pp. 549-570.

Menietti, Michael, Maria Recalde, and Lise Vesterlund, "Public good games with interior Nash equilibria: advantages of the piece-wise linear VCM," mimeo, 2014.

Noussair, C. and K. Matheny, "An experimental study of decisions in dynamic optimization problems," Economic Theory, 2000, 15 (2), 389-419.

Saijo, T., K. Sherstyuk, N. Tarui, and M. Ravago, "Games with Dynamic Externalities and Climate Change Experiments," mimeo, 2013.

Vespa, E., "Cooperation in Dynamic Games: An Experimental Investigation," mimeo, 2014.

Vesterlund, Lise, "Using Experimental Methods to Understand Why and How We Give to Charity," mimeo, 2013.

Volden, C. and A.E. Wiseman, "Bargaining in legislatures over particularistic and collective goods," American Political Science Review, 2007, 101 (1), 79. 


\section{Appendix A: Proofs}

\section{The Efficient Solution}

The maximization problem specified in section 2.1 can be re-written using the following notation $X_{1} \equiv \sum_{i=1}^{n} x_{i 1}$ and $X_{2} \equiv \sum_{i=1}^{n} x_{i 2}$ :

$$
\begin{gathered}
\max _{I_{1}^{P}, I_{2}^{P}}\left[B_{1}-I_{1}^{P}+n \cdot u\left(I_{1}^{P}\right)+B_{2}-I_{2}^{P}+n \cdot u\left(\delta I_{1}^{P}+I_{2}^{P}\right)\right] \\
\text { s.t. } 0 \leq I_{1}^{P} \leq B_{1} \text { and } 0 \leq I_{2}^{P} \leq B_{2}
\end{gathered}
$$

There are several cases to deal with depending on which, if any, constraints are binding. If no constraints are binding, then there is an interior solution, $\left(I_{1}^{P^{*}}, I_{2}^{P^{*}}\right)$ characterized by two first order conditions:

$$
\begin{aligned}
u^{\prime}\left(\delta I_{1}^{P^{*}}+I_{2}^{P^{*}}\right) & =\frac{1}{n} \\
u^{\prime}\left(I_{1}^{P^{*}}\right)+\frac{\delta}{n} & =\frac{1}{n}
\end{aligned}
$$

If the solution is not interior, there are several ways the constraints can be binding. One possibility is that $I_{1}^{P} \leq B_{1}$ is binding. A second possibility is that $0 \leq I_{2}^{P}$ is binding. A third possibility is that $I_{2}^{P} \leq B_{2}$ binds, but this is an uninteresting case and in the rest of the paper we assume it never binds. Notice that the constraint $0 \leq I_{1}^{P}$ is never binding because of the Inada condition on $u$. The constraint $0 \leq I_{2}^{P}$ is binding when the value of $I_{1}^{P^{*}}$ that solves $(1)$ is such that $u^{\prime}\left(\delta I_{1}^{P^{*}}\right)<\frac{1}{n}$, which happens if $\delta$ is sufficiently large. In this case, as long as $I_{1}^{P} \leq B_{1}$ is not also binding, the solution is given by:

$$
u^{\prime}\left(I_{1}^{P^{*}}\right)+\delta u^{\prime}\left(\delta I_{1}^{P^{*}}\right)=\frac{1}{n}
$$

the second equation of (1), with $I_{2}^{P^{*}}=0$. If both $I_{1}^{P} \leq B_{1}$ and $0 \leq I_{2}^{P}$ bind, then the solution is $I_{1}^{P^{*}}=B_{1}, I_{2}^{P^{*}}=0$. If only $I_{1}^{P} \leq B_{1}$ is binding, then the solution is given by the first equation of (??, with $I_{1}^{P^{*}}=B_{1}$. Finally, observe that our assumptions on $u$ implies a unique planner solution $\left(I_{1}^{P^{*}}, I_{2}^{P^{*}}\right)$.

In our experiments, the utility of the public good is given by $u(g)=A g^{\alpha}$ and parameters $B_{1}$ and $B_{2}$ are large enough so that the budget constraints are not binding. Thus, the efficient solution depends on the value of $\delta$ :

$$
\text { if } \delta^{1-\alpha}<1-\delta \text { then }\left\{\begin{array}{l}
I_{1}^{P^{*}}=\left[\frac{1-\delta}{n A \alpha}\right]^{\frac{1}{\alpha-1}} \\
I_{2}^{P^{*}}=\left[\frac{1}{n A \alpha}\right]^{\frac{1}{\alpha-1}}-\delta\left[\frac{1-\delta}{n A \alpha}\right]^{\frac{1}{\alpha-1}}
\end{array}\right.
$$




$$
\text { if } \delta^{1-\alpha} \geq 1-\delta \text { then }\left\{\begin{array}{l}
I_{1}^{P^{*}}=\left[\frac{1}{n A \alpha\left(1+\delta^{\alpha}\right)}\right]^{\frac{1}{\alpha-1}} \\
I_{2}^{P^{*}}=0
\end{array}\right.
$$

\section{The Bargaining Equilibrium}

\section{Period 2}

The randomly chosen proposer only needs to gain the support of $\frac{n-1}{2}$ other members of the committee. Denote by $x_{2}^{\mathrm{Pr}}$ the private allocation the proposer will keep for herself and by $x_{2}^{\mathrm{C}}$ the amount she will give to $\frac{n-1}{2}$ non-proposer committee members 'in her coalition'. Then, her maximization problem is given by:

$$
\begin{gathered}
\max _{\left(x_{2}^{\mathrm{Pr}}, x_{2}^{\mathrm{C}}, I_{2}^{L}\right)}\left[x_{2}^{\mathrm{Pr}}+u\left(g_{2}\right)\right] \\
\text { s.t. }\left\{\begin{array}{l}
x_{2}^{\mathrm{Pr}}+\frac{n-1}{2} \cdot x_{2}^{\mathrm{C}}+I_{2}^{L} \leq B_{2} \\
x_{2}^{\mathrm{C}}+u\left(g_{2}\right) \geq V_{2}\left(I_{1}\right) \\
0 \leq I_{2}^{L}, 0 \leq x_{2}^{\mathrm{Pr}}, 0 \leq x_{2}^{\mathrm{C}} \\
g_{2}=\delta I_{1}^{L}+I_{2}^{L}
\end{array}\right.
\end{gathered}
$$

where $I_{1}^{L}$ is the level of public good implemented in period 1 of the legislative bargaining game, $V_{2}\left(I_{1}^{L}\right)$ is the value of the game in the second period, as a function of $I_{1}^{L}$, before a proposer has been selected. The first constraint involves re-writing the budget constraint using the symmetry assumption. In other words, the private allocation for the proposer plus an equal amount assigned to each other member of a minimum winning coalition (MWC) cannot be higher than the available funds after investment $\left(B_{2}-I_{2}^{L}\right)$, where subscript $L$ stands for the legislature. The second constraint guarantees the participation of other coalition members. A non-proposer who is included in the coalition will vote in favor of the proposal if the utility he gets from it (LHS) is at least as high as the equilibrium expected value of rejecting it $\left(V_{2}\right)$. The remaining constraints are feasibility constraints. Being a strictly concave problem, there will be a unique solution for the equilibrium period 2 investment level, $I_{2}^{L}$. Assuming an interior solution, $0 \leq I_{2}^{L} \leq B_{2}$, it is characterized by:

$$
u^{\prime}\left(\delta I_{1}^{L}+I_{2}^{L}\right)=\frac{2}{n+1}
$$

In period 2 , the proposer weighs the marginal benefit to the public good to the coalition of $\frac{n+1}{2}$ voters against the marginal cost in units of private good of investing an extra unit in the public good.

FOC (3) captures the optimal period 2 investment in the bargaining game as a function of the investment in the first period, $I_{1}$. As in the analysis of the planner's solution, it is possible that $u^{\prime}\left(\delta I_{1}^{L}\right)<\frac{2}{n+1}$, in which case (3) violates the constraint $0 \leq I_{2}^{L}$. Thus, the full characterization of 
how $I_{2}^{L}$ varies as a function of $I_{1}^{L}$ is the following:

$$
I_{2}^{L}\left(I_{1}^{L}\right)=\left\{\begin{array}{l}
u^{\prime-1}\left[\frac{2}{n+1}\right]-\delta I_{1}^{L} \text { if } u^{\prime}\left(\delta I_{1}^{L}\right) \geq \frac{2}{n+1} \\
0 \text { otherwise }
\end{array}\right.
$$

The funds remaining once the unique optimal investment level has been determined are simply $B_{2}-I_{2}^{L}\left(I_{1}^{L}\right)$. These remaining funds will be allocated among committee members just as in a Baron-Ferejohn multilateral bargaining game with no public good, giving:

$$
\begin{aligned}
x_{2}^{\mathrm{C}} & =\frac{1}{n}\left(B_{2}-I_{2}^{L}\left(I_{1}\right)\right) \\
x_{2}^{\mathrm{Pr}} & =\frac{n+1}{2 n}\left(B_{2}-I_{2}^{L}\left(I_{1}\right)\right)
\end{aligned}
$$

Finally, we can also use the equilibrium levels of these allocations to compute the equilibrium continuation value in period $2, V_{2}\left(I_{1}\right)$ :

$$
V_{2}\left(I_{1}^{L}\right)=\frac{1}{n}\left(B_{2}-I_{2}^{L}\left(I_{1}^{L}\right)\right)+u\left(\delta I_{1}^{L}+I_{2}^{L}\left(I_{1}\right)\right)
$$

\section{Period 1}

The selected period 1 proposer anticipates how her decisions will impact choices in period 2 . The maximization problem of the proposer in period 1 can be written as:

$$
\begin{gathered}
\max _{\left(x_{1}^{\mathrm{Pr}}, x_{1}^{\mathrm{C}}, I_{1}^{L}\right)}\left[x_{1}^{\mathrm{Pr}}+u\left(I_{1}^{L}\right)+V_{2}\left(I_{1}^{L}\right)\right] \\
\text { s.t. }\left\{\begin{array}{l}
x_{1}^{\mathrm{Pr}}+\frac{n-1}{2} x_{1}^{\mathrm{C}}+I_{1}^{L} \leq B_{1} \\
x_{1}^{\mathrm{C}}+u\left(I_{1}^{L}\right)+V_{2}\left(I_{1}^{L}\right) \geq V_{1} \\
0 \leq I_{1}^{L} \leq B_{1}, 0 \leq x_{1}^{\mathrm{Pr}}, 0 \leq x_{1}^{\mathrm{C}}
\end{array}\right.
\end{gathered}
$$

where $V_{1}$ is the expected value of the game to each player before a proposer has been selected. The function to maximize includes the proposer's period 1 utility and the equilibrium expected value of the game for period 2, which depends on $I_{1}^{L}$. Maximization is constrained by the budget and by the fact that any coalition member expects the proposal to provide at least as much as he would receive by rejecting it $\left(V_{1}\right)$. The first constraint obviously holds with equality. If the second constraint is binding and the feasibility constraints are not binding (i.e., the solution is interior), then the maximization problem for the proposer in period 1 can be rewritten as:

$$
\max _{I_{1}^{L}}\left[B_{1}-I_{1}^{L}-\frac{n-1}{2} V_{1}+\frac{n+1}{2}\left[u\left(I_{1}^{L}\right)+V_{2}\left(I_{1}^{L}\right)\right]\right]
$$


The first order condition that characterizes the equilibrium investment in period $1, I_{1}^{L}$ is:

$$
u^{\prime}\left(I_{1}^{L}\right)+\left.\frac{d V_{2}}{d I_{1}}\right|_{I_{1}^{L}}=\frac{2}{n+1}
$$

The left hand side again reflects the distortions from the planner's solution due to a combination of free rider effects (both dynamic and static) and the bargaining advantage of the period 1 proposer. There are two separate dynamic effects, because $I_{1}^{L}$ affects $V_{2}$ in two ways: there is a direct effect on the level of public good in period 2, which we refer to as the durability effect; second, there is an indirect effect on the equilibrium private allocations in period 2, which we call the crowding-out effect.

$$
\left.\frac{d V_{2}}{d I_{1}}\right|_{I_{1}^{L}}=-\left.\frac{1}{n} \frac{d I_{2}^{L}}{d I_{1}}\right|_{I_{1}^{L}}+\left[\delta+\left.\frac{d I_{2}^{L}}{d I_{1}}\right|_{I_{1}^{L}}\right] u^{\prime}\left[\delta I_{1}^{L}+I_{2}^{L}\left(I_{1}^{L}\right)\right]
$$

Case 1: Interior solution. At an interior solution (i.e., $I_{1}^{L}<B_{1}$ and $I_{2}^{L}\left(I_{1}^{L}\right)>0$ ), $\frac{d I_{2}}{d I_{1}}=-\delta$, so the first term reduces to $\frac{\delta}{n}$, and the second term vanishes because the increased period 1 investment completely crowds out period 2 investment. Hence in this case, the entire dynamic free riding effect is due to the indirect crowding-out effect, that is, $\left.\frac{d V_{2}}{d I_{1}}\right|_{I_{1}^{L}}=\frac{\delta}{n}$. Substituting back into the first order condition for the equilibrium period 1 proposal, 5 , gives:

$$
u^{\prime}\left(I_{1}^{L}\right)+\frac{\delta}{n}=\frac{2}{n+1}
$$

Thus, the crowding out effect actually reduces the free rider problem, since the (interior) value of $I_{1}^{L}$ that solves (7) is strictly higher than the solution if $\delta=0$, and is actually increasing in $\delta$. The intuition behind this is that the period 1 proposer can reduce the side payments to coalition members by increasing $V_{2}$ (by freeing up more period 2 budget for private allocations), and raises her own payoff at the same time.

Case 2: Corner solution, $I_{2}^{L}\left(I_{1}^{L}\right)=0$. If in equilibrium the constraint $0 \leq I_{2}$ binds, then $\frac{d I_{2}}{d I_{1}}=0$, and the first term vanishes. In this case, investment in period 1 will not substitute for investment in period 2 at the margin. Hence in this case, the entire dynamic free riding effect is due to the direct durability effect. That is, $\left.\frac{d V_{2}}{d I_{1}}\right|_{I_{1}^{L}}=\delta u^{\prime}\left(\delta I_{1}\right)$. Substituting back into the first order condition for the equilibrium period 1 proposal, 5 , gives:

$$
u^{\prime}\left(I_{1}^{L}\right)+\delta u^{\prime}\left(\delta I_{1}^{L}\right)=\frac{2}{n+1}
$$

Given functional form used in our experiments $u(g)=A g^{\alpha}$, the equilibrium investment levels in the legislative bargaining game are given by: 


$$
\begin{aligned}
& \text { if } \delta^{1-\alpha}<1-\delta \frac{n+1}{2 n} \text { then }\left\{\begin{array}{l}
I_{1}^{L^{*}}=\left[\frac{1-\frac{n+1}{2 n} \delta}{\frac{n+1}{2} A \alpha}\right]^{\frac{1}{\alpha-1}} \\
I_{2}^{L^{*}}=\left[\frac{1}{\frac{n+1}{2} A \alpha}\right]^{\frac{1}{\alpha-1}}-\delta\left[\frac{1-\frac{n+1}{2 n} \delta}{\frac{n+1}{2} A \alpha}\right]^{\frac{1}{\alpha-1}}
\end{array}\right. \\
& \text { if } \delta^{1-\alpha} \geq 1-\delta \frac{n+1}{2 n} \text { then }\left\{\begin{array}{l}
I_{1}^{L^{*}}=\left[\frac{1}{\frac{n+1}{2} A \alpha\left(1+\delta^{\alpha}\right)}\right]^{\frac{1}{\alpha-1}} \\
I_{2}^{L^{*}}=0
\end{array}\right.
\end{aligned}
$$

Finally, we note that it is straightforward generalizes analysis presented here to any quota voting rule, where a proposal passes if a winning coalition requires at least $q$ individuals, where $q$ is any integer from 1 to $n$. The main idea is that the free riding problem is linked directly the fact that a proposer will only internalize the value to $q$ members of the legislature, since that is all she needs for the proposal to pass. When $q=n$, there is no free rider problem, and the optimal public investment is the equilibrium investment.

\section{Appendix B: Instructions}

Below we present the instructions for our $D B 80$ treatment. Periods are referred to as Rounds.

\section{Written instructions}

\section{Welcome}

You are about to participate in an experiment on decision making and you will be paid for your participation with cash vouchers, privately at the end of the session. The currency in this experiment is called tokens. All payoffs are denominated in this currency. Tokens that you earn in the experiment will be converted into US dollars using the rate 10 Tokens $=\$ 1$. In addition, you will get $\$ 10$ participation fee if you complete the experiment. The money you earn will depend on your decisions, the decisions of others and chance.

Do not talk to or attempt to communicate with other participants during the session. Please make sure to turn off phones, mp3 players and pagers now. The session will begin with a brief instructional period, during which you will be informed of the main features of the task and you will be shown how to use the computer.

\section{Basic Steps}

In this experiment you will act as voters that distribute funds between yourself and others in a series of rounds. Each round consists of two periods. In each period you must decide on how to split a sum of money between yourself, two others and a group project. Proposals will be voted up 
or down (accepted or rejected) by majority rule; i.e., for proposals to pass they must get 2 or more votes.

Each round starts with Period 1. Your three-member group will have to decide how to divide 200 tokens. To do this each member of the group will submit a proposal that specifies how the 200 tokens are divided between you, the two other voters and the group project.

After you have all made your proposals, one of them will be selected at random to be voted on. All proposals have equal probability of being selected. The proposed allocation will be posted on your computer screens and you will have to decide whether to accept or reject it.

- If the proposed allocation passes (gets 2 or more votes) - it is binding and you move on to the Period 2.

- If the proposal is defeated (gets less than 2 votes), there will be a call for new proposals. This process will repeat itself until a proposed allocation passes (gets 2 or more votes).

In Period 2, the group will again have to allocate 200 tokens between you, two other voters and the group project. The process is the same: each member of the group starts by submitting a proposal.

The difference with the previous Period is that part of what the group allocated to the group project in Period 1 is still available in Period 2. In other words, the project size at the beginning of Period 2 is $80 \%$ of the amount invested in the group project in Period 1. For example, if the group project that passed in Period 1 was 15 tokens, then the project size at the beginning of Period 2 is 12 tokens. The total project size at the end of Period 2 will be the project size at the beginning of Period 2 (which is 12 tokens in our example) plus the investment in the group project in Period 2.

After you have all made your proposals, one of the proposed allocations will be selected at random to be voted on and you will have to decide whether to accept or reject it.

- If the proposed allocation passes (gets 2 or more votes) - it is binding and you move on to Period 1 in a new Round.

- If the proposal is defeated (gets less than 2 votes), there will be a call for new proposals and the process will repeat itself until a proposed allocation passes (gets 2 or more votes).

\section{Payoffs}

Your Payoff in Period 1 depends only on the proposed allocation that passed:

$$
\left.\begin{array}{ccc}
\text { Your } & \text { Your } \\
\text { Payoff } & =\begin{array}{c}
\text { Investment } \\
\text { In Period } 1
\end{array} & \text { in Period } 1
\end{array}\right)^{0.5}
$$

Your Payoff in Period 2 depends on the proposed allocation that passed and on the size of the group project at the beginning of Period 2 .

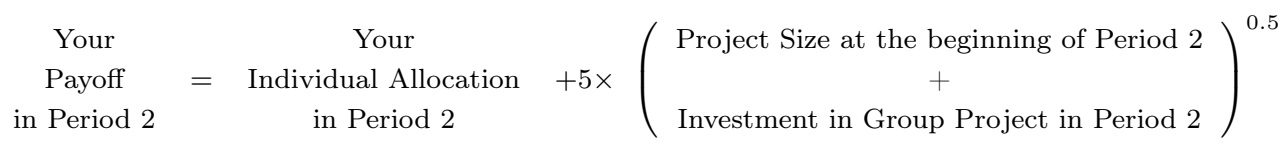

When you are considering what proposal to submit, the computer interface will let you compute the payoffs implied by your proposal for each voter of the group. 


\section{Number of rounds}

In this session there will be total of 10 rounds with two periods in each round. Before the beginning of each round, participants in the experiment will be divided randomly to the groups of 3 voters. The identity of your group members will never be revealed to you and your group members will never know your identity. You will stay in the same group in both periods of a round. Once the second period of the round is over, you will be randomly allocated to a new group of 3 voters.

\section{How tokens are converted into cash payments}

At the conclusion of the experiment, one of the 10 rounds played for tokens will be randomly selected by computer, and the tokens you earned in this round (both in the first and in the second period) will be converted into US dollars using a conversion rate of 10 Tokens $=\$ 1$. In addition you will receive the $\$ 8$ participation fee for completing the experiment.

\section{To summarize}

- The experiment consists of 10 rounds. In each round participants are assigned to groups of 3 voters in each. Each round consists of two periods.

- In each Period all members of the group submit a proposal to allocate 200 tokens between a group project and individual allocations to each of the 3 voters. One of these proposals is selected at random and is voted on by all group members. All proposals have equal chance of being selected.

- Tokens allocated to the group project yield positive payoffs for all group members, while tokens allocated to the individual members of the group benefit only those members.

- The allocation passes if two or more voters accept it. If the allocation passes in Period 1, the group moves on to Period 2.

- If the allocation passes in Period 2, a new Round will begin. If the allocation is rejected, then there will be a call for new proposals.

- Your payoff in Period 1 depends on your individual allocation in Period 1 and the group investment in Period 1.

- The project size at the beginning of Period 2 is $80 \%$ of the investment in the Group Project in Period 1.

- Your payoff in Period 2 depends on your individual allocation in Period 2, the investment in the Group Project in Period 2 and the size of the Group Project at the beginning of Period 2.

- Total payoff in the round $=$ Payoff in Period $1+$ Payoff in Period 2 . 
- Once the round is over, participants are randomly assigned to new groups of 3 voters in each and the next round begins, which is identical to the previous one.

- At the end of the experiment, one round is chosen randomly by the computer, and the tokens earned in this round are converted into US dollars, added to the participation fee and paid to participants in cash vouchers.

\section{Script and slides}

This script was read aloud while projecting some slides. See Figure 3 to follow most instructions. Comments between brackets were not read aloud.

\section{Script}

We will now conduct a practice round that will not count for money. As we move on this practice round please do not click or enter any information until I ask you to. If you have any questions raise your hand.

The experiment will take place over a sequence of 10 matches. We begin the match by dividing you into committees of three members each. Each of you is assigned to exactly one of these committees. In each match your committee will make budget decisions by majority over a sequence of two rounds.

[SHOW SLIDE $\mathrm{A} 1+\mathrm{A} 2+\mathrm{A} 3+\mathrm{P}=200]$

[point while reading] In each round your committee has a budget of 200. Your committee must decide how to divide this budget into four categories, in integer amounts: the first three categories are the private allocations and they always have to be greater than or equal to 0 . The fourth category is for investment in a project and it also must be greater than or equal to 0 .

If your committee's budget decision is (A1, A2, A3, P), then A1 go directly to member 1's earnings, A2 to member 2 and A3 to member 3. The project investment produces earnings for all committee members in the following way.

The project earnings in a round depend on the size of the project at the end of that round. Specifically, each committee member earns an amount in points proportional to the square root of the size of the project at the end of the round (precisely equal to $5^{*}$ sqrt(project size) ). During the experiment, there will be a graph on the screen that shows exactly how project earnings will depend on project size.

\section{[SHOW SLIDE GRAPH]}

For example, if the size of the project at the end of the round equals 121, then each member earns exactly $5 * \operatorname{sqrt}(121)$ or 55 additional points in that round. If the size is equal to 25 , each member earns exactly $5^{*}$ sqrt(25) or 25 additional points in that round. In your display, earnings are always rounded to two decimal places. So, for example if the project size at the end of a round equals 70 , each member earns 41.83 points from the project in that round. 
As we said before, there are two rounds. The project size at the end of round 1 is simply what the committee allocated to the project in round $1.80 \%$ of the amount invested in the project in round 1 carries over to round 2, so project size at the beginning of round 2 is $80 \%$ of project size in round 1 . Finally project size at the end of round 2 is the project size at the beginning of round 2 plus the investment in the project in round 2 .

At the end of each round your earnings for that round are computed by adding the project earnings to your private allocation. For example, if your private allocation is 20 and the end-ofround project size is 121 , then your earnings for that round equal $20+5^{*} \operatorname{sqrt}(121)=20+5^{*} 11=$ 75. Your earnings for the match equal the sum of the earnings in both rounds of that match.

After the first match ends, we move to match 2. In this new match, you are reshuffled randomly into new committees of three members each. The match then proceeds the same way as match 1 .

We will now go through one practice match very slowly. During the practice match, please do not hit any keys until I tell you, and when you are prompted by the computer to enter information, please wait for me to tell you exactly what to enter. You are not paid for this practice match.

\section{[AUTHENTICATE CLIENTS-Start Multistage]}

Please double click on the icon on your desktop that says BP2. When the computer prompts you for your name, type your First and Last name. Then click SUBMIT and wait for further instructions.

[accept and start game] [screenshot]

You now see the first screen of the experiment on your computer. It should look similar to this screen. [POINT]

You have been assigned by the computer to a committee of three subjects, and assigned a committee member number: 1, 2 or 3 . This committee assignment and your member number stay the same for both rounds of this match, but will change across matches. It is very important that you take careful note of your committee member number.

Your committee decides on a budget for this round by the following voting procedure. First, every member is asked to type in a provisional budget proposal, consisting of four integers, A1, A2, A3 and P, which add up to 200. A1, A2, A3 and P have to be greater than or equal to 0 .

Ok. In the example... committee member \# individual allocations should be entered here project investment here. As we proceed note that any information pertaining to you specifically will be in red.

[point to graph as appropriate, while reading this]

As a visual aid, there is a graph on the left that shows exactly how project earnings will depend on project size. The current size of the project is marked with a large dot. If your committee decides to invest nothing this period, then this will be the size that determines your project earnings at the end of the round. You can use your mouse to move the cursor along the curve to figure out what your earnings will be for different levels of investment. Also, if you type in a budget amount in the Project box, the computer will compute and display the corresponding project earnings for you just below the box. 
Take a minute to practice using your cursor to move along the curve, and typing in different possible investment levels for the Project. But do not hit the confirm button yet.

[wait one minute]

At this time, go ahead and type in any provisional proposal you wish and hit the confirm button. You are not paid for this practice match so it does not matter what you enter.

[wait for responses] [screenshot]

After everyone in your committee has submitted a provisional budget proposal, your screen should now look similar to this one [POINT]. The computer has randomly selected one of the provisional budget proposal submitted by the members of your committee to be the Round One Proposed Budget in your committee. In the top-right of your screen you are shown this proposed budget as well as which committee member made this proposal. [POINT]

[ In this example Again: member Number Current project size Proposer Proposed budget. These numbers are random Note that when information is displayed in a quadruple, it is always listed in order of memberNumber. So... Also note : I am member 3, so the number is red.] At this moment all committee members are asked to vote on the Proposed Budget. The decision is made by majority rule. The Proposed Budget passes if it receives 2 or 3 votes. Otherwise, it fails, there will be a call for new proposals and the process will repeat itself until a proposed budget passes (gets 2 or 3 votes). To vote to accept the Proposed Budget, click on the "yes" button; to reject it, click on the "no" button. Please go ahead and vote "yes" now. Since this is a practice round that doesn't count for money please all click on "yes" button.

[wait for responses] [screenshot]

[point] In addition to your committee member number, you can see each member's vote, the outcome of the vote, and the end of round project size. You can also see your earnings in round 1 and the project size in the beginning of round 2.

[In this example Again, in order: memberNumber Votes Outcome End-Of-Round project size]

This marks the end of the round.

The table with columns in the bottom of your screen is the History panel and summarizes all of this important information.

[Go BRIEFLY over history panel]

[click to advance to next round] [screenshot]

Now the second round begins. In this second round, you keep the same committee member number as in the first round, and the members of your committee all stay the same. Notice that $80 \%$ of the project investment from round 1 carries over, so the round 2 beginning project size equals 0.8 times the project size at the end of round 1 .

[In this example Project size upper right hand corner Project size at origin of graph]

In this second round each member of the committee is asked to submit Provisional Budget Proposal of how to divide 200 between yourself, two other committee members and project investment. Please enter your Provisional Budget Proposal now.

[screenshot] 
One of the proposals was randomly chosen to be voted on. [In this example proposal]

On the graph, you can see the project size if this proposal will pass. At this time all committee members are asked to vote on the chosen budget proposal. If two or three members of the committee vote yes, then the proposal will pass and this will be the end of the match. If the proposal will fail then there will be a call for new proposals and the process repeats itself until the proposal is passed. You can now finish this round, by voting "yes" on the budget proposal.

[screenshot] [wait for them to finish]

Finally on this screen you see the proposal that passed and your earnings for this round.

Now we are ready for the comprehension quiz. Everyone must answer all the questions correctly before we go to the paid matches. The quiz has four pages. You must answer all the questions on Page 1 of the quiz to proceed to Page 2, and you must answer all the questions on Page 2 of the quiz to proceed to Page 3, etc.... If you answer any of the questions on a page incorrectly, you will be asked to try again. Please raise your hand if you have any questions during the quiz, and we will come to your desk and answer your question in private.

[reassure them its ok to ask for help]

[Quiz detailed below]

[WAIT FOR END OF QUIZ]

Are there any questions before we begin with the paid session?

[WAIT FOR QUESTIONS]

We will now begin with the first of 10 paid matches of the experiment. If there are any problems or questions from this point on, raise your hand and an experimenter will come and assist you in private.

\section{Quiz}

\section{Handout in the instructions}

[Not read: Extra handout to subjects that the experimenter reads with the subjects]

Before we start with the experiment we ask you to answer a few questions related to the instructions. You can make up to $\$ 4$ if you answer these questions correctly. The table below is provided to familiarize you with the payoffs and help you when you answer the questions. The first column shows possible allocations to the Group Project in Period 1 from 200 to 0 with changes of 10 tokens. The second column displays how the investment in the group project will be transformed into tokens for payoffs. The third column shows what will be available for individual allocations in Period 1. The fourth column shows the part of the Period 1 Investment in the Group Project that will be available in Period 2: The Size of the Project at the beginning of Period 2. The last column displays the portion of Period 2 payoffs that comes from the Project Size at the beginning of Period 2 . 


\begin{tabular}{|c|c|c|c|c|}
\hline \multirow{2}{*}{$\begin{array}{c}\text { Investment in } \\
\text { Group Project }\end{array}$} & $\begin{array}{c}\text { Period 1 PAYOFF coming } \\
\text { in Period 1 }\end{array}$ & $\begin{array}{c}\text { Period 1 Budget remaining } \\
\text { for Individual Allocations }\end{array}$ & $\begin{array}{c}\text { Group Project Size of Project } \\
\text { at the Beginning of Period 2 }\end{array}$ & $\begin{array}{c}\text { Period 2 PAYOFF coming } \\
\text { from Investment in Period 1 }\end{array}$ \\
\hline 200 & $\left.\begin{array}{c}\text { Investment in } \\
\text { Group Project } \\
\text { in Period 1 }\end{array}\right)$ & $\left.\begin{array}{c}0.5 \\
\text { Investment in } \\
\text { Group Project } \\
\text { in Period 1 }\end{array}\right)$ & $80 \% \times\left(\begin{array}{c}\text { Investment in } \\
\text { Group Project } \\
\text { in Period 1 }\end{array}\right)$ & $\left.\begin{array}{c}\text { Group Project Size } \\
\text { at the beginning } \\
\text { of Period 2 }\end{array}\right)$ \\
\hline 190 & 70.71 & 0 & 160 & 63.25 \\
\hline 180 & 68.92 & 10 & 152 & 61.64 \\
\hline 170 & 67.08 & 20 & 144 & 60.00 \\
\hline 160 & 65.19 & 30 & 136 & 58.31 \\
\hline 150 & 63.25 & 40 & 128 & 56.57 \\
\hline 140 & 61.24 & 50 & 120 & 54.77 \\
\hline 130 & 59.16 & 60 & 112 & 52.92 \\
\hline 120 & 57.01 & 70 & 104 & 50.99 \\
\hline 110 & 54.77 & 80 & 96 & 48.99 \\
\hline 100 & 52.44 & 90 & 88 & 46.90 \\
\hline 90 & 50.00 & 100 & 80 & 44.72 \\
\hline 80 & 47.43 & 110 & 72 & 42.43 \\
\hline 70 & 44.72 & 120 & 64 & 40.00 \\
\hline 60 & 41.83 & 130 & 56 & 37.42 \\
\hline 50 & 38.73 & 140 & 48 & 34.64 \\
\hline 40 & 35.36 & 150 & 40 & 31.62 \\
\hline 30 & 31.62 & 160 & 32 & 28.28 \\
\hline 20 & 27.39 & 170 & 24 & 24.49 \\
\hline 10 & 22.36 & 180 & 16 & 20.00 \\
\hline 0 & 15.81 & 190 & 8 & 14.14 \\
\hline & 0.00 & 200 & 0 & 0.00 \\
\hline
\end{tabular}

\section{Questions as they appear on the screens}

\section{Screen 1}

1. For a budget proposal, what do your Private Investments and Project Investment have to add up to? a) 50; b)100; c)200; d) 250

2. There are two rounds in each match. a) True; b) False. There are ten rounds in each match. c)False. The number of rounds in each match depends on the roll of the die.

3. Your committee member number stays the same throughout the experiment. a) True; b) False. Your committee member number stays the same in every round of a match, but is reassigned for new matches.

4. You are reshuffled into a different committee for each match. a) True; b) False. You are in the same committee in all matches.

\section{Screen 2}

1. In round 1, assume that in the allocation supported by a majority of committee members the Project Investment is 30 and your individual allocation is 20. How much of your payoff would come from the Project Investment? a) 50; b) 38.73; c) 27.39; d) 65.19

2. How much of your payoff would come from the individual allocation? a) 30; b) 100; c) 20; d) 170

3. What size is the Project Investment at the beginning of round 2 ? a) 48; b) 24 ; c) 72 ; d) 112

4. How much of your payoff in round 2 would come from the Project Investment in round 1? a) 112.25 ; b) 24.49 ; c) 58.31 ; d) 15.81 ; e) 20 
Screen 3

1. In round 1, assume that in the allocation supported by a majority of committee members the Project Investment is 100 and your individual allocation is 20 . How much of your payoff would come from the Project Investment? a) 50; b) 38.73 ; c) 57.01 ; d) 65.19

2. How much of your payoff would come from the individual allocation? a) 30; b) 100; c) 20; d) 170

3. What size is the Project Investment at the beginning of round 2 ? a) 72 ; b) 88 ; c) 80 ; d) 40

4. How much of your payoff in round 2 would come from the Project Investment in round 1? a) 44.72 ; b) 25.50 ; c) 50.99 ; d) 22.36

\section{Screen 4}

1. In round 1, assume that in the allocation supported by a majority of committee members the Project Investment is 170 and your individual allocation is 20. How much of your payoff would come from the Project Investment? a) 171.03; b) 189.74; c) 206.76 ; d) 195.58

2. How much of your payoff would come from the individual allocation? a) 30; b) 100; c) 20; d) 170

3. What size is the Project Investment at the beginning of round 2? a) 144; b) 128; c) 136; d) 120

4. How much of your payoff in round 2 would come from the Project Investment in round 1? a) 30 ; b) 58.31 ; c) 129.15 ; d) 60

\section{Appendix C: Further Analysis at the Aggregate Level}

\section{Number of Stages}

The data shows a high proportion of accepted first-stage proposals, similar to levels previously reported in the literature (see for example Fréchette et al. 2003). If we consider the last five matches in all treatments aggregating both periods the percentage of accepted proposals is above $80 \%$ and the median number of stages required is one. Figure 4 shows for each period and treatment the average number of stages needed for a proposal to pass as the session evolves.

\section{Minimum Winning Coalitions}

Table 9 summarizes information with respect to MWCs in our dataset. Several patterns, common to all treatments, emerge from the table. First, the proportion of MWCs is statistically higher in the second period than in the first period. 


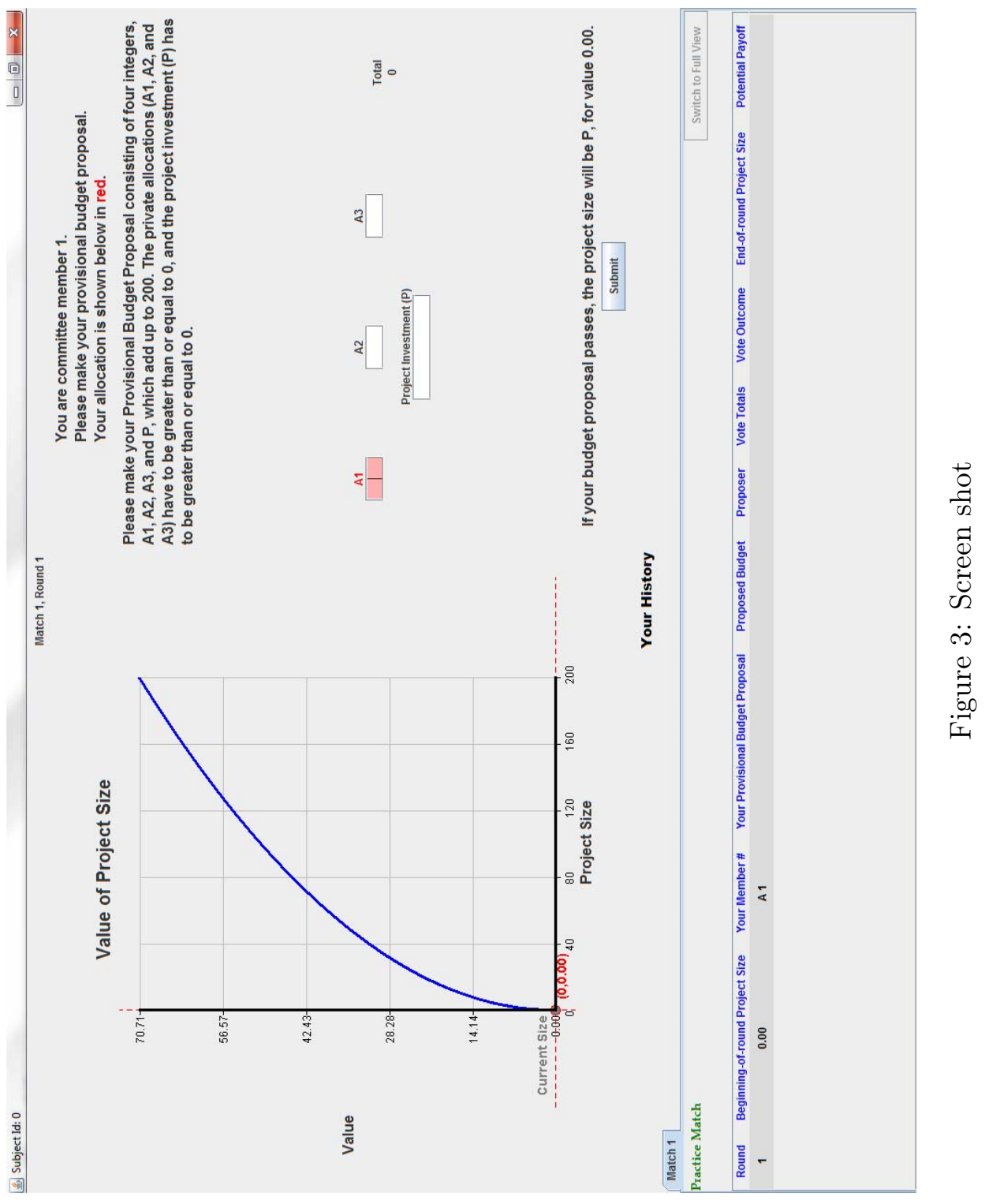



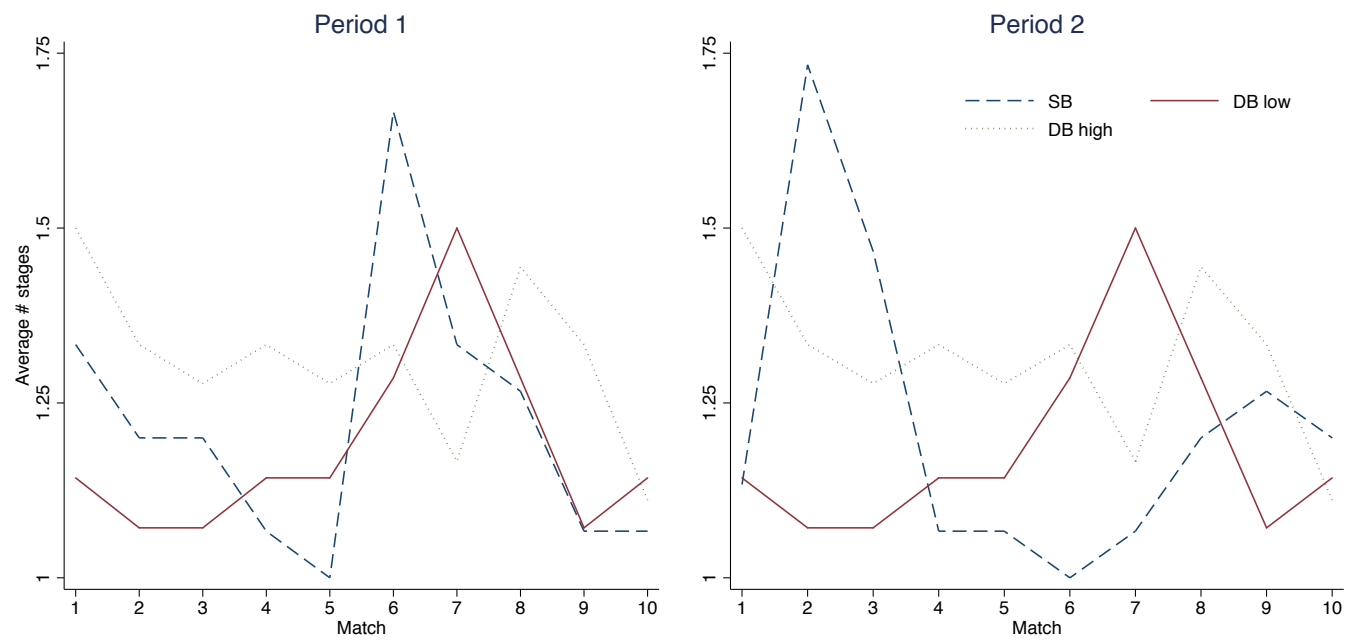

Figure 4: Average Number of Stages

Table 9: Proposals involving Minimum Winning Coalitions (in \%)

\begin{tabular}{cc|cc}
\hline Treatment & & All Matches & Last Five \\
\hline \multirow{3}{*}{$S B$} & Period 1 & 55.6 & 66.2 \\
& Period 2 & 67.8 & 84.4 \\
& Both & 51.3 & 63.6 \\
\hline \multirow{3}{*}{ DB ${ }^{\text {low }}$} & Period 1 & 27.1 & 32.4 \\
& Period 2 & 52.1 & 64.3 \\
& Both & 26.2 & 33.3 \\
\hline \multirow{3}{*}{ DB $B^{\text {high }}$} & Period 1 & 33.5 & 37.4 \\
& Period 2 & 65.6 & 78.2 \\
& Both & 31.7 & 36.3 \\
\hline
\end{tabular}

Second, as subjects gain experience with the environment, they use MWCs more often. With the exception of the $D B^{\text {high }}$ treatment, in all cases the number of proposals involving MWC is statistically higher when we focus on the last five matches. Third, almost all subjects proposing a MWC in the first period behave likewise in the second. The corresponding proportion reported in the third row of each treatment captures how many subjects proposed MWCs in both periods and this figure closely follows the one reported for the first period.

There are also differences across treatments. First, when there is full depreciation ( $S B$ treatment) period 1 rates are on average higher than compared to other treatments (though this difference is not statistically significant). In the $D B$ treatments only about a third of proposals involve MWCs in the first period, the lowest figures of the table. This difference almost disappears when we compare second period rates. Second, although in some cases the differences are small, rates are slightly higher in the $D B^{\text {high }}$ treatment when compared to the $D B^{\text {low }}$ treatment. 


\section{Period 1 investment}

Figure 5 displays the histograms for Period 1 investment across treatments and for different subsets of proposals: all, proposals that passed and proposals involving MWCs. Investment is heavily concentrated around the bargaining equilibrium prediction in the SB case, but is relatively more spread out in $\mathrm{DB}$ treatments. In almost every $D B$ case we observe two modes for investment, one relatively close to the bargaining equilibrium and a second closer to the planner's solution. The exception is the $D B^{h i g h}$ case for proposals involving MWCs, where most investment levels are relatively closer to the bargaining equilibrium. 
SB Treatment
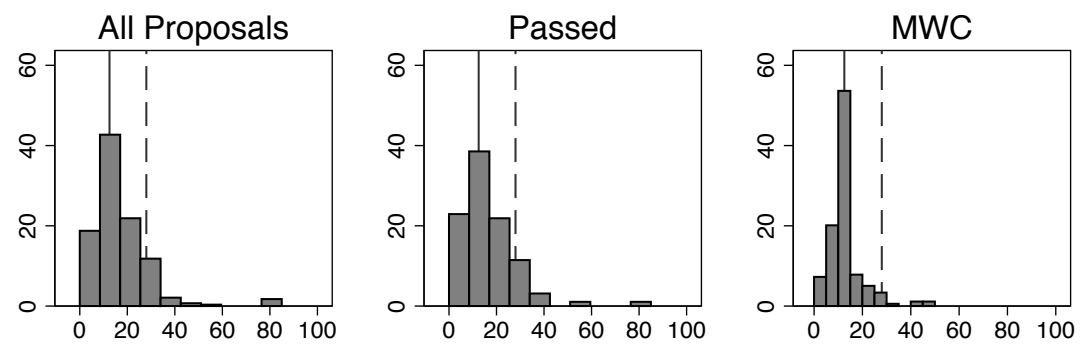

\section{DB20 Treatment}
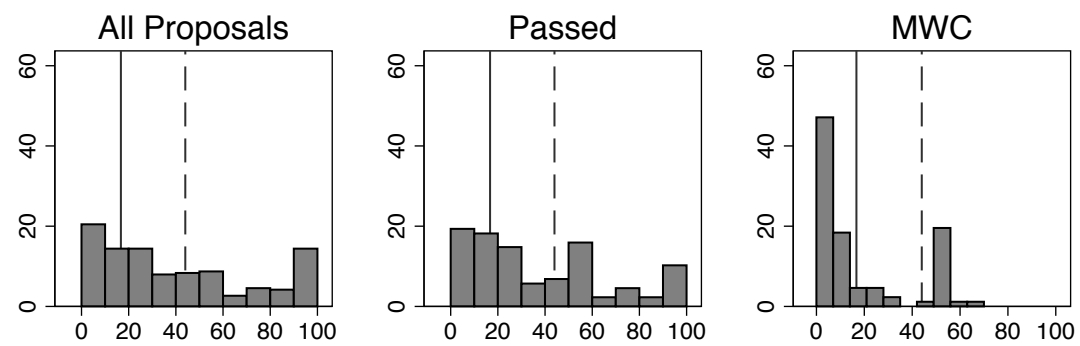

\section{DB80 Treatment}
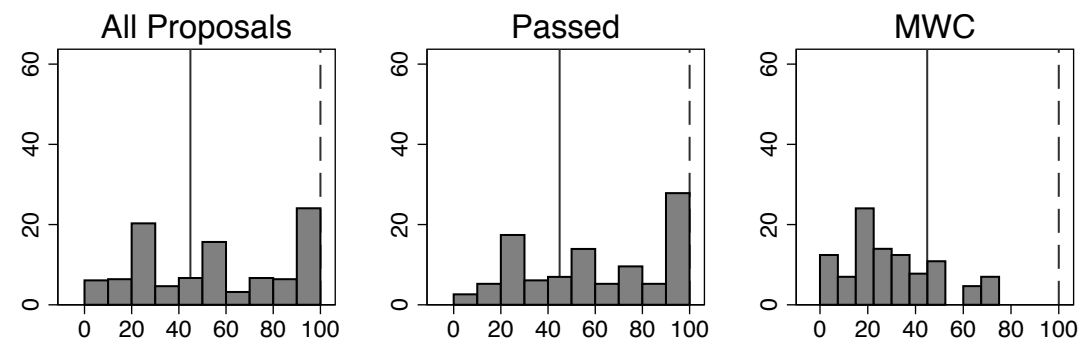

Figure 5: Distribution of Period 1 Investment as \% of Budget Solid lines: Bargaining equilibrium; Dashed lines: Planner's solution Vertical axis measures the $\%$ of proposals in the corresponding bin 

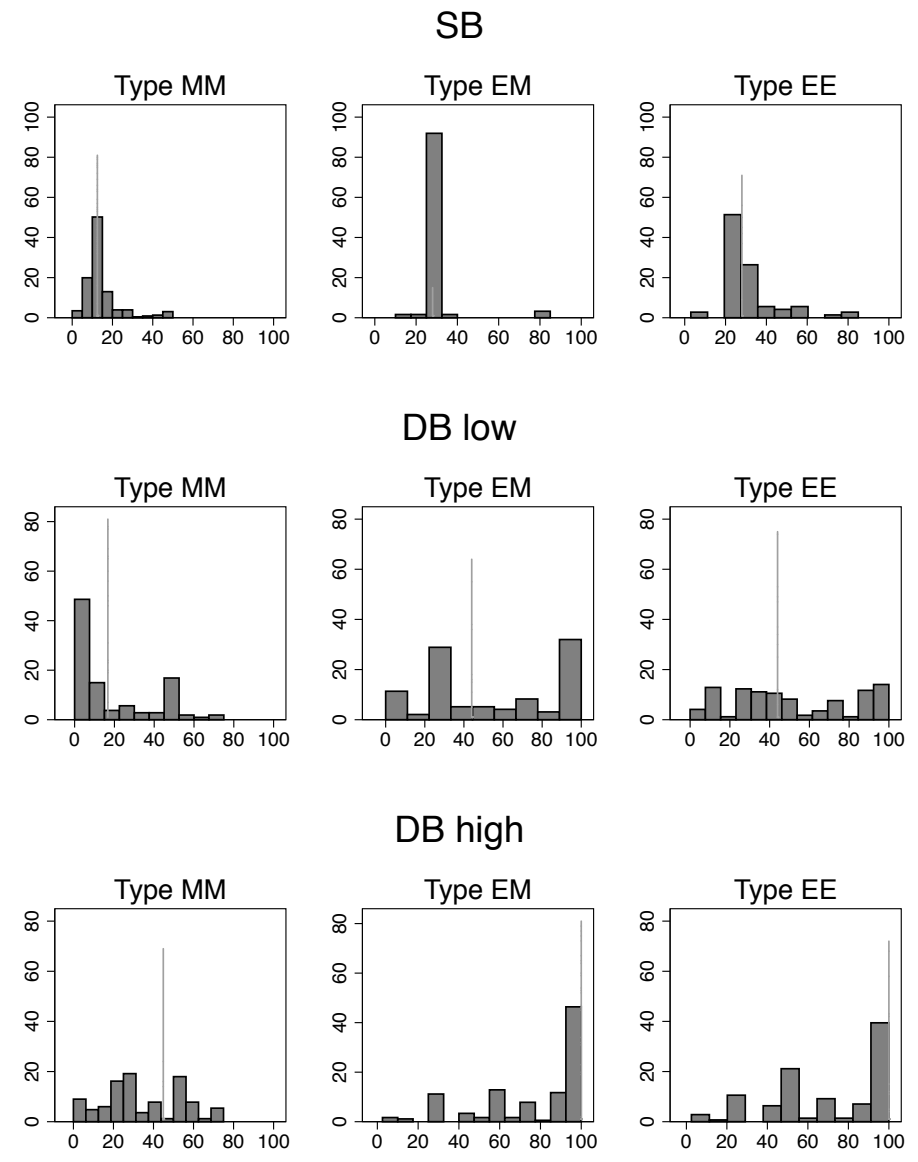

Figure 6: Distribution of Period 1 Investment as \% of Budget

Lines: Theory predictions

\section{Appendix D: Further Analysis at the Individual Level}

\section{Distribution of Investment in Period 1}

Figure 6 displays the distribution of period 1 investment by treatment and by strategy type for the last 5 matches of each session.

\section{Distribution of Private Allocations}

Private allocations capture how the budget remaining after public investment is divided among committee members and Table 10 summarizes the relevant information. For each treatment there are two statistics: the allocation to the proposer $\left(x^{P r}\right)$ and the allocation to a non-proposer in the coalition $\left(x^{N P r}\right) .{ }^{31}$ The 'theory' values presented in the table correspond to the bargaining

\footnotetext{
${ }^{31}$ In proposals satisfying definition $\mathrm{A}, x^{N P r}$ is computed for each proposal as the average to both coalition members other than the proposer.
} 
Table 10: Private allocations as \% of Budget

\begin{tabular}{|c|c|c|c|c|c|c|c|c|c|c|c|c|c|}
\hline \multirow{3}{*}{\multicolumn{2}{|c|}{ Treatment }} & \multicolumn{4}{|c|}{ Type MM } & \multicolumn{4}{|c|}{ Type EM } & \multicolumn{4}{|c|}{ Type EE } \\
\hline & & \multicolumn{2}{|c|}{ Period 1} & \multicolumn{2}{|c|}{ Period 2} & \multicolumn{2}{|c|}{ Period 1} & \multicolumn{2}{|c|}{ Period 2} & \multicolumn{2}{|c|}{ Period 1} & \multicolumn{2}{|c|}{ Period 2} \\
\hline & & Theory & Med. & Theory & Med & Theory & Med & Theory & Med & Theory & Med & Theory & Med \\
\hline \multirow{2}{*}{$S B$} & $x^{P r}$ & 58.4 & 45.0 & 58.4 & 45.0 & 24.0 & 25.0 & 58.4 & 45.0 & 24.0 & 25.0 & 24.0 & 25.0 \\
\hline & $x^{N P r}$ & 29.1 & 42.5 & 29.1 & 42.5 & 24.0 & 25.0 & 29.1 & 45.0 & 24.0 & 25.0 & 24.0 & 25.0 \\
\hline \multirow{2}{*}{$D B^{\text {low }}$} & $x^{P r}$ & 55.6 & 45.0 & 60.1 & 50.0 & 18.7 & 16.5 & 60.1 & 50.0 & 18.7 & 20.0 & 26.9 & 25.0 \\
\hline & $x^{N P r}$ & 27.8 & 45.0 & 30.3 & 49.0 & 18.7 & 15.0 & 30.3 & 50.0 & 18.7 & 20.0 & 26.9 & 25.0 \\
\hline \multirow{2}{*}{$D B^{h i g h}$} & $x^{P r}$ & 36.8 & 35.0 & 66.7 & 49.5 & 0 & 5.0 & 66.7 & 50.0 & 0 & 10.0 & 33.3 & 23.5 \\
\hline & $x^{N P r}$ & 18.4 & 35.0 & 33.3 & 45.0 & 0 & 5.0 & 33.3 & 50.0 & 0 & 10.0 & 33.3 & 23.5 \\
\hline
\end{tabular}

equilibrium for Type MM proposals and to the identified theoretical candidate within each type in other cases.

Proposals involving MWCs should reflect proposer power: allocations should theoretically double that of the Non-Proposer coalition member. To test for the presence of proposal power we construct the ratio between the allocation to the proposer and the non proposer in the coalition $\left(x^{P r} / x^{N P r}\right)$. We then use a random effects model and regress that ratio on a constant (see footnote ?? for more details). Under the null hypothesis of no proposal power, the coefficient estimated on the constant is not different than one. We cannot reject the null only in the case of Type MM proposals in the $S B$ treatment. In that case, there is a small presence of proposal power at levels comparable to previous reports in the literature (see for example Fréchette et al. (2003)). There is no evidence of proposal power in $D B$ treatments.

\section{Strategy Types as the session evolves}

For each subject we fix the strategy type they select in match 6 and we compute the likelihood they select each possible type in matches 7-10. We report the probabilities in Table 11.

A few patterns emerge. First, there is a high persistence of the most popular strategy types. Type MM strategies are the most popular in the $S B$ treatment and a large majority of subjects selecting those strategies in match 6 (82.5\%), stick to that type for the remainder of the session. Similar conclusions apply, for example, for Type MM and Type EM strategies in the DB80 treatment. Second, for those who select Type EM in match 6, but change afterwards the most popular transition is towards Type MM strategies. Third, for those who select Type EE in match 6, the most popular switch is to Type EM proposals.

An alternative point of view to study how subjects transition among strategies is to consider the proportion of subjects who use only one strategy type or more during a session. Table 12 shows for each treatment the proportion of subjects who use only one type, two types or all types. Slightly more than $20 \%$ of subjects across treatments use all three strategy types. Most subjects use two strategy types with the groups: 'Type MM and Type EM' and 'Type EM and Type EE' being the 
Table 11: Transitions from type in match 6 to latter matches

\begin{tabular}{c|c|cccc}
\multirow{3}{*}{ Treatment } & \multirow{2}{*}{ Type in Match 6 } & \multicolumn{4}{|c}{ Prob. selects each strategy type in matches 7-10 (in \%) } \\
& Type MM & Type EM & Type EE & Other \\
\hline \multirow{3}{*}{$S B$} & Type MM & 82.5 & 13.3 & 0.0 & 4.2 \\
& Type EM & 20.8 & 42.5 & 8.3 & 12.5 \\
& Type EE & 8.3 & 29.2 & 25.0 & 37.5 \\
& Other & 41.7 & 0.0 & 0.0 & 58.3 \\
\hline \multirow{3}{*}{$D B 20$} & Type MM & 71.2 & 9.6 & 9.6 & 9.6 \\
& Type EM & 36.1 & 61.1 & 0.0 & 2.8 \\
& Type EE & 2.9 & 27.9 & 64.7 & 4.4 \\
& Other & 16.7 & 58.3 & 25.0 & 0.0 \\
\hline \multirow{5}{*}{$D B 80$} & Type MM & 77.6 & 10.5 & 6.6 & 5.3 \\
& Type EM & 13.8 & 78.8 & 7.5 & 0.0 \\
& Type EE & 4.2 & 37.5 & 52.1 & 6.3 \\
& Other & 50.0 & 8.3 & 0.0 & 41.7
\end{tabular}

Table 12: Proportion of subjects who use one, two, or all strategy types

\begin{tabular}{c|ccc|} 
& \multicolumn{3}{|c|}{ Treatment } \\
& $S B$ & $D B^{\text {low }}$ & $D B^{\text {high }}$ \\
\hline Only Type MM & $15.6 \%$ & $4.8 \%$ & $9.3 \%$ \\
Only Type EM & $0.0 \%$ & $0.0 \%$ & $0.0 \%$ \\
Only Type EE & $0.0 \%$ & $9.5 \%$ & $3.7 \%$ \\
Type MM and Type EM & $31.1 \%$ & $26.2 \%$ & $29.6 \%$ \\
Type MM and Type EE & $15.6 \%$ & $9.5 \%$ & $3.7 \%$ \\
Type EM and Type EE & $15.5 \%$ & $28.6 \%$ & $29.6 \%$ \\
All Types & $22.2 \%$ & $21.4 \%$ & $24.1 \%$
\end{tabular}

most popular.

\section{Strategies of type MM and EM: Payoff Comparison}

Given that strategies type MM and typeEM remain popular in both $D B$ treatments towards the end of the session, we inspect further differences in payoffs between them. To do this we take the place of a period 1 proposer and consider her alternatives. That is, we focus on subjects who were proposers in period 1 and compare earnings depending on whether they submitted a proposal that satisfies Definition A or not.

For type EM proposals to be attractive, there should be a period 2. Thus, we look at period 2 payoffs of period 1 proposers, $u_{2}=x_{2}^{P 1}+f\left(g_{2}\right)$, and estimate $u_{2}=\alpha_{0}+\alpha_{1} A 1+\epsilon$. A positive estimate for $\alpha_{1}$ would suggest that using a strategy type EM in period 1 increases payoffs in period 2. The last column of Table 13 presents the estimates for $\alpha_{1}$, which are significant at the $5 \%$ level for all treatments. Quantitatively, additional payoffs imply an extra $15 \%$ in the second period. The extra gain in period 2 comes at the cost of a lower period 1 payoff: in comparison to the bargaining 
Table 13: Period 1 Payoff Levels: Accepted Proposals

\begin{tabular}{c|c|c|c||c}
\multirow{2}{*}{ Treatment } & \multicolumn{3}{|c||}{ Mean Period 1 Payoffs to proposers } & Additional Period 2 \\
& Type MM & Type EM & Type EE & Payoff if A1=1 \\
\hline$B S$ & 112.6 & 85.5 & 85.4 & 13.6 \\
$B D 20$ & 107.4 & 80.1 & 81.7 & 15.2 \\
$B D 80$ & 105.5 & 76.0 & 78.2 & 14.5
\end{tabular}

Table 14: Type EM strategies: Punishment and Rewards Random Effects Estimates

\begin{tabular}{|c|c|c|c|c|c|c|}
\hline \multirow[b]{2}{*}{ Variable } & \multicolumn{2}{|r|}{$S B$} & \multicolumn{2}{|c|}{$B D 20$} & \multicolumn{2}{|c|}{$D B 80$} \\
\hline & Coeff. & Rob. Sd. Err. & Coeff. & Rob. Sd. Err. & Coeff. & Rob. Sd. Err. \\
\hline Constant & $20.50^{* * *}$ & $(1.26)$ & $19.52^{* * *}$ & $(2.35)$ & $22.29^{* *}$ & $(1.25)$ \\
\hline$A 1$ & $2.60^{* * *}$ & $(0.98)$ & 1.79 & $(2.89)$ & -2.59 & $(1.31)$ \\
\hline EM $M_{\text {strategy }}$ & -6.36 & $(4.56)$ & $-9.07 * * *$ & $(2.63)$ & $-2.74 * * *$ & $(3.08)$ \\
\hline$A 1 \times E M_{\text {strategy }}$ & 4.92 & $(13.29)$ & $15.54^{* *}$ & $(7.97)$ & $12.09^{* * *}$ & $(4.07)$ \\
\hline Number of Observations & 300 & & 280 & & 360 & \\
\hline
\end{tabular}

solution, a proposal closer to the planner's implies higher payoffs for the committee as a whole, but lower payoffs for the proposer. Table 13 shows mean period 1 payoffs to the proposer, depending on proposal type. There are negligible differences between type EM and EE proposals, but such proposals lag compared to type MM: on average they represent between 72 and $76 \%$ of type MM payoffs depending on treatment. Yet, if we add the additional period 2 payoff the differences shrink: a proposal of type EM involves between 86 and $89 \%$ of payoffs from a type M-M proposal.

\section{Type EM strategies: Punishments and Rewards estimates}

Table 14 provides the estimates used for our computations in Table 8.

\section{Determinants of Voting}

Now we study the features that determine whether a proposal passes or not. This exercise can also help to understand why some strategy types are selected. If, for example, a proposal type EM or type EE was more likely to be voted up in period 1, then it may be more likely to be selected vis a vis a proposal involving a MWC. We focus on stage 1, period 1 proposals that were submitted for voting and estimate

$$
\text { vote }_{i m}=1\left\{\beta_{0}+\beta_{1}\left(f\left(I_{1}\right)_{i m}\right)+\beta_{2} x_{1, i m}+\beta_{3} x_{1, i m}^{P r}+\beta_{4} E_{i m}+\beta_{5} M W C_{i m}+\alpha_{i}+\nu_{i m} \geq 0\right\}
$$

where vote $_{i m}$ is a dummy variable that takes value 1 if subject $i$ approved the proposal in match $m$, and $1\{\cdot\}$ is an indicator function that takes value one if the left-hand side of the inequality inside the braces is greater than or equal to zero and the value zero otherwise. Explanatory variables include the investment payoff $\left(f\left(I_{1}\right)\right)$, the private period 1 allocation $\left(x_{1}\right)$, the allocation to the proposer $\left(x_{1}^{P r}\right)$ and dummy variables for whether the proposal involves an Equal Split $(E)$ or a MWC. The 
Table 15: Period 1 Voting: Random Effects Probit (Marginal Effects)

\begin{tabular}{|c|c|c|c|c|c|c|}
\hline \multirow[b]{2}{*}{ Variable } & \multicolumn{2}{|c|}{$S B$} & \multicolumn{2}{|c|}{ BDlow } & \multicolumn{2}{|c|}{ DBhigh } \\
\hline & Coefficient & Rob. Std. Err. & Coefficient & Rob. Std. Err. & Coefficient & Rob. Std. Err. \\
\hline Investment Payoff & $0.023^{*}$ & $(0.013)$ & $0.032^{* * *}$ & $(0.010)$ & $0.039^{* * *}$ & $(0.011)$ \\
\hline Private Allocation & $0.057^{* * *}$ & $(0.067)$ & $0.050 * * *$ & $(0.007)$ & $0.048^{* * *}$ & $(0.006)$ \\
\hline Proposer Private Allocation & $-0.023^{* * *}$ & $(0.007)$ & $-0.023^{* * *}$ & $(0.006)$ & $-0.025^{* * *}$ & $(0.005)$ \\
\hline MWC & $0.608^{*}$ & $(0.335)$ & 0.230 & $(0.372)$ & 0.045 & $(0.254)$ \\
\hline Equal Split & 0.118 & $(0.210)$ & 0.254 & $(0.268)$ & 0.226 & $(0.228)$ \\
\hline Number of Observations & 450 & & 420 & & 540 & \\
\hline
\end{tabular}

equation is estimated using a random effects probit, with a one-way subject error component for all rounds. Table 15 reports the corresponding marginal effects.

The coefficients provide evidence that there is a positive effect of investment payoff and private allocations on the probability of voting positively for a proposal and a negative effect from higher private allocations to the proposer. This is consistent with previous estimates in the literature (see Fréchette et al. (2003, 2005)). Estimates on the Definition A and M dummies are positive, but not significant in the $D B$ treatments. This suggests that there is not a particular gain in terms of higher likelihood of a proposal passing because it involves an Equal Split or a MWC. 